\title{
A pesquisa médica e biomédica no Brasil. Comparações com o desempenho científico brasileiro e mundial
}

\author{
Medical and biomedical research in Brazil. \\ A comparison of Brazilian and international \\ scientific performance
}

Jorge A. Guimarães 1

\footnotetext{
1 Presidente da Capes Coordenação de Aperfeiçoamento de Pessoal de Nível Superior. Esplanada dos Ministérios, Bloco L Anexo II, 2o andar. 70.359-970 Brasília DF. pr@capes.gov.br
}

\begin{abstract}
This article compares Brazil's performance in science and technology investment to that of other countries, in relation to basic research, application of knowledge, and researcher training. The article shows a high correlation between GDP and scientific and technological performance in developed countries such as the United States, Japan, Germany, United Kingdom, France, Canada, Italy, China, Russia, and Spain, and demonstrates how this occurs in medium development countries like Mexico, India, and Brazil. The data presented were obtained from various sources: the Research Group Directory and Lattes Platform of the Brazilian National Research Council (CNPq-MCT); Science Indicators; Institute for Scientific Information (ISI); World Development Indicators (WDI); Web of Science of the ISI; and the CAPES - FAPESP agreement, Brazil. The comparison to higher-performance countries gave a clearer grasp of Brazil's health research challenge in order to increase the citation indices and better qualify such research.
\end{abstract}

Key words Comparative research in health, Science and technology policy, Brazilian technological development, Investment in health research
Resumo Este texto coloca o Brasil no interior dos países que fazem investimento em C\&T, de forma comparada, no que concerne a pesquisas básicas, à aplicação do conhecimento e à formação de pesquisadores. Evidencia elevada correlação entre o (PIB) e o desempenho científico e tecnológico de países desenvolvidos como EUA, Japão, Alemanha, Inglaterra, França, Canadá, Itália, China, Rússia e Espanha, e mostra como isso se realiza em países de médio desenvolvimento como México, Índia e Brasil. Os dados apresentados foram extraídos de diversas fontes: Diretório dos Grupos de Pesquisa e Plataforma Lattes, CNPq-MCT; Science Indicators; Institute for Scientific Information (ISI); World Development Indicators (WDI); Web of Science do ISI, acordo Capes - Fapesp, Brasil. A comparação com os países de mais elevado desempenho possibilita melhor situar o desafio a ser vencido pela pesquisa brasileira na área da saúde, para colocá-la no patamar dos índices de citação que melhor qualifica a pesquisa feita na área.

Palavras-chave Pesquisa comparada em saúde, Política de C\&T, Desenvolvimento tecnológico brasileiro, Investimento em pesquisa em saúde 


\section{Introdução}

Ciência e tecnologia (C\&T) e educação qualificada são atividades cada vez mais reconhecidas como componentes fundamentais para o desenvolvimento econômico, vale dizer, tecnológico e industrial das nações. Indissociavelmente associadas nos países desenvolvidos e também naqueles com desenvolvimento recente, educação e C\&T compõem as bases essenciais de um ciclo virtuoso que subsidia o crescente progresso socioeconômico desses países. De fato, observa-se entre os países mais desenvolvidos uma elevada correlação entre o Produto Interno Bruto (PIB) e o desempenho científico e tecnológico. Entre os dez mais destacados em desempenho em C\&T (EUA, Japão, Alemanha, Inglaterra, França, Canadá, Itália, China, Rússia e Espanha) esta correlação é majoritariamente observada. Neste particular, países com PIB também expressivo, como México (mais acentuadamente), Índia e Brasil ainda não apresentam tal correlação. Diferentemente verifica-se que a correlação inexiste quando a comparação do desempenho científico é feita em relação à população desses e de outros países.

Igualmente reconhecido é o sistema educacional desses países em todos os níveis. Destaque-se também que o componente educacional vem constituindo a base de suporte ao desempenho de países emergentes no contexto da produção em C\&T, como é o caso da China, Coréia do Sul e Taiwan. Acrescente-se, ademais, que é igualmente reconhecida nesses países a importância tanto da pesquisa básica quanto da pesquisa aplicada. Esta correlação decorre da constatação, que se comprova na prática, de que a proposição de patentes é cada vez mais fundamentada com conhecimentos científicos básicos gerados no próprio país. Como demonstrado por Narim, Hamilton e Olivastro (1997), nas patentes americanas de desenvolvimento tecnológico industrial, a contribuição das citações da pesquisa acadêmica (subsidiada majoritariamente com recursos públicos) vem crescendo rapidamente, tendo triplicado no período 1991-1996. Atualmente, 73\% das informações científicas que subsidiam a proposição das patentes industriais americanas estão fundamentadas e provêm das pesquisas e publicações do setor acadêmico; somente $27 \%$ das citações nas patentes provêm dos pesquisadores da indústria. Um forte componente de nacionalização dessa combinação - citações acadêmicas X patentes industriais - foi tam- bém encontrado pelos autores no Reino Unido, na França, no Japão e na Alemanha, onde tais patentes citam preferencialmente os trabalhos científicos básicos produzidos pelo setor acadêmico de cada país. Essas observações são mais pertinentes à ciência moderna publicada em revistas de alta qualificação e proveniente de projetos financiados por agências públicas de fomento à pesquisa nesses países.

No Brasil, o complexo educacional universitário e, conseqüentemente, o sistema de C\&T foram ambos estruturados muito tardiamente e estão, ainda, em processo de consolidação. Ademais, nossos processos de ensino na educação fundamental e mesmo na graduação universitária, predominantemente informativos que privilegiam a memorização em detrimento do processo formativo, vêm se mostrando bastante deficitários e perigosamente defasados da demanda por um ensino qualificado. Não obstante, apesar da juventude do nosso sistema educacional e científico, nas últimas quatro décadas houve considerável avanço no segmento de Ciência e Tecnologia no Brasil, um desempenho claramente mostrado pelos indicadores internacionais. De fato, a produção científica brasileira cresceu, nas últimas décadas, em um nível excepcional, confirmado pelas publicações qualificadas pela indexação no Institute for Scientific Information (ISI, Filadélfia, EUA). Entre os 30 países mais destacados no ranking da ciência mundial os quais são responsáveis por $90 \%$ dessa produção, o crescimento do Brasil, em tão curto espaço de tempo, só foi menor do que o de alguns poucos países desse conjunto, que também tiveram crescimento excepcional: Coréia do Sul, Taiwan, China, Espanha e Turquia.

Destaque-se também que o desempenho da ciência brasileira carece ainda da uniformidade observada nos países mais desenvolvidos. Muitas áreas, com capacitação de recursos humanos ainda não consolidada apresentam desempenho modesto. Assim, nosso crescimento em C\&T vem sendo garantido pelas áreas mais consolidadas, destacando-se, entre essas, física, medicina, química, ciências biomédicas e subáreas das ciências agrárias, das engenharias e ciências humanas e sociais. Este artigo destaca o desempenho da área médica, com suas 31 subáreas ou disciplinas e das ciências biomédicas no Brasil nas duas últimas décadas. Inicialmente são apresentados dados da ciência brasileira como um todo e feitas algumas comparações com a ciência mundial e depois apresentados e 
discutidos dados do desempenho nas áreas selecionadas para o trabalho.

\section{Metodologia}

Os dados apresentados neste trabalho foram levantados e extraídos de diversas fontes:

1) Diretório dos Grupos de Pesquisa (Censo 2002) e Plataforma Lattes, CNPq-MCT, Brasília, DF, Brasil, <http://www.cnpq.gov.br >;

2) Capes: <www.capes.gov.br >;

3) Science Indicators 2001 disponibilizado em CD-Rom. Institute for Scientific Information (ISI) Filadélfia, EUA;

4) World Development Indicators (WDI) World Bank Groups, World Bank, 2001, <http: //www.worldbank.org/> e <http://www.world bank.org/data/wdi2001>;

5) Web of science, também do ISI obtido pelo acordo Capes - Fapesp, Brasil, <http://webof science.fapesp.br $>$.

Os dados relativos à produção científica quali-quantitativa foram levantados e extraídos dos bancos de dados do Institute for Scientific Information (ISI) da Filadélfia (EUA). Tais informações foram obtidas de duas bases de dados do ISI:

a) Web of Science, disponibilizado on line pelo Programa Periódicos da Capes: $<$ http://webofscience.capes.br>;

b) Science Indicators 2001, disponibilizado em CD-Rom. Esta base de dados possibilita dois tipos de acesso às áreas do conhecimento. No acesso Standard todas as áreas estão compactadas em 24 áreas ou campos de pesquisa. Neste acesso, a medicina é área única, identificada como "Clinical Medicine" e algumas áreas das ciências biomédicas identificadas como tal. Já o acesso Deluxe, expande de 24 para 105 as áreas, campos ou subáreas, e aí estão incluídas 30 subáreas da medicina e 11 das ciências biomédicas, cujo levantamento detalhado só pôde ser feito a partir do acesso Deluxe para propiciar distinção de subáreas pertencentes, por exemplo, às ciências biológicas ou à área biomédica.

Ao longo deste texto e, especialmente no rodapé das tabelas e figuras as fontes Standard ou Deluxe são identificadas para melhor esclarecimento ao leitor. Ressalte-se que nos acessos às bases de dados do ISI, a identificação das áreas resulta da classificação feita pelo próprio ISI, vinculando as revistas e periódicos a cada uma das áreas. No acesso Standard do Science Indicators 2001, estão listadas as 6.954 revistas científicas mundiais indexadas no ISI, enquanto no Deluxe existem 8.403 revistas, representando uma sobreposição de cerca de $20,8 \%$ de periódicos classificados em mais de um área. Isso justifica a dupla contagem no número de artigos encontrada nas análises feitas e indicadas ao longo do trabalho. Na grande área médica a sobreposição de periódicos é de $20 \%$ ( 1.307 revistas no Standard e 1.568 no acesso Deluxe) e na área biomédica essa sobreposição é de $4,9 \%$ entre as duas bases ( 816 periódicos na base Standard e 856 na base Deluxe). Devido à sobreposição de revistas entre áreas e subáreas, mais acentuada na base Deluxe, há também dupla contagem de artigos para essas áreas. Tal situação ocorre também entre países, tendo como base os trabalhos em colaboração. Os índices de dupla contagem estão indicados nas situações pertinentes em cada tabela.

Vale notar que a classificação das áreas com base nas revistas aí identificadas pode, eventualmente, introduzir alguma distorção na avaliação do desempenho da área. Este é o caso, por exemplo, da área de fisiologia nos trabalhos publicados no Brazilian Journal of Medical and Biological Research (BJMBR). Estes artigos (em números significativos no caso dos fisiologistas brasileiros) estão, todavia, listados na medicina já que o BJMBR é classificado pelo ISI como pertencente exclusivamente à área médica. Também devido à vinculação da área com as revistas ali classificadas, a área de odontologia e cirurgia bucal está incluída no ISI como área médica, enquanto que saúde coletiva é classificada como pertencente às ciências sociais. Vale, então, informar que no presente trabalho, a fisiologia é analisada nas ciências biomédicas, com seus dados extraídos do Science Indicators 2001, base Deluxe como lá estão indicados, portanto, sem as correções relativas às publicações no BJMBR; a área odontologia e cirurgia bucal é mantida como área médica como no ISI e os dados da saúde coletiva foram incluídos pelo autor na área médica. Também para efeito de melhor compreensão, menciona-se que dois tipos de publicações são identificadas no artigo: a) no Science Indicators 2001, somente artigos completos publicados em revistas indexadas no ISI e b) no Web of Science, além de artigos completos podem ser também levantadas outras publicações como cartas, comentários, editoriais e eventualmente resumos, sempre que publicados em revistas indexadas no ISI. Para os dados do Brasil, no ano de 2001, a diferença publicações totais/artigos completos foi de $27 \%$, 
mas nos dados mundiais, tal relação pode chegar a mais de $60 \%$. Essas diferenças têm, não raramente, produzido distorções na avaliação do desempenho da ciência brasileira.

Ressalte-se finalmente que como ocorre nos países desenvolvidos tecnologicamente, as publicações científicas: a) indicam a capacitação e a qualificação científica de cada país, especialmente nas comparações mundiais; b) são a garantia de produção de novos conhecimentos, um acervo básico que fundamenta a geração de novas patentes, como indicado por Narim et al. (1997). Nesta análise estão computadas somente as publicações nas revistas e periódicos indexados na base de dados do ISI, que inclui alguns (infelizmente ainda poucos) periódicos brasileiros ali indexados. Portanto, o estudo não inclui uma considerável quantidade de outros artigos, publicados em revistas nacionais de áreas específicas, cujas publicações tratam de temas que, com freqüência, têm maior inserção e relevância local e regional. A estimativa é de que, incluídas estas publicações, os números da produção científica brasileira seriam pelo menos duplicados. Entretanto, para os objetivos da comparação internacional, prevista para este artigo, não foi possível incluir os dados dessa produção ainda não de todo internacionalizada.

Neste trabalho não foi considerada a diferença dos investimentos dos países no segmen- to de C\&T. Sabe-se, todavia, que este fator pesa substancialmente no desempenho quali-quantitativo da produção científica de cada um dos países. Neste sentido, vale lembrar que os países mais desenvolvidos do ranking de desempenho apresentado neste trabalho investem de $2 \%$ a 3\% do seu PIB em C\&T e que este investimento representa um índice 3 a 5 vezes mais elevado do que o investimento que vem sendo feito pelo Brasil nos últimos anos.

\section{Desempenho científico do Brasil}

Os avanços da produção científica brasileira são assim ilustrados: na década de 1960 a média das publicações científicas divulgadas em periódicos indexados na base de dados do ISI, era de 52 artigos científicos anuais. A figura 1 ilustra o crescimento da produção científica brasileira nas últimas três décadas. Em 1970 foram apenas 64 artigos, representando 0,019\% da produção mundial naquele ano. Em 2001, a produção brasileira catalogada naquela base de dados foi de 10.555 artigos completos e de 13.353 incluindo outras publicações igualmente indexadas, significando um crescimento de 165 vezes das nossas publicações completas qualificadas! Isto corresponde a 76 vezes o crescimento da produção mundial, que foi de apenas 2,18 vezes no período: de 337.378 em 1970 pa-

\section{Figura 1}

Publicações brasileiras indexadas (ISI) por ano: 1973-2001.

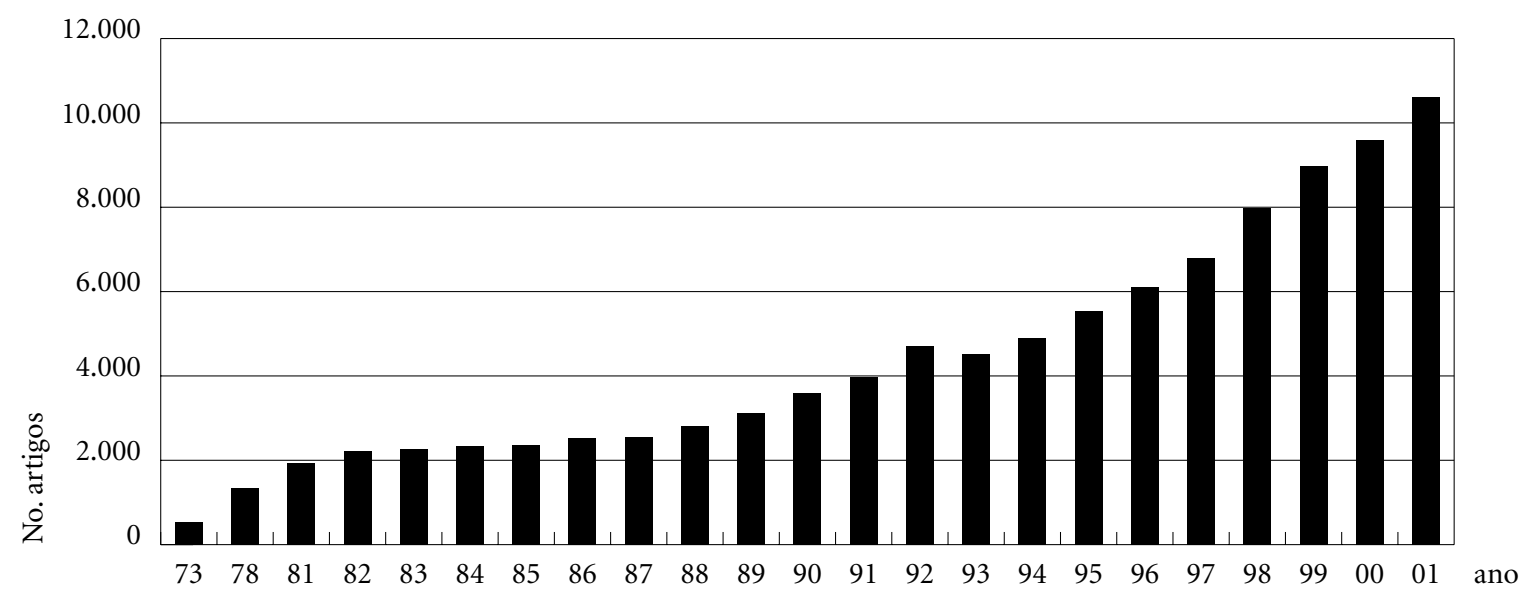

Fonte: Science Indicators - (ISI) / CD-Rom - 2001 e Web of Science - (ISI) 
ra 734.248 artigos completos (1.201.561 incluindo outras publicações) no ano de 2001. Esse ritmo de crescimento manteve-se acentuado a partir dos anos 70 como mostra a figura 1.

No período mais recente e também mais competitivo (1981-2001), a ciência brasileira experimentou crescimento ainda mais significativo quando consideradas as publicações indexadas pelo ISI (Guimarães \& Gomes, 2001; Gomes \& Guimarães, 2001). A figura 2 ilustra o crescimento relativo da produção brasileira nesse período relativamente aos índices de crescimento mundial. Verifica-se que o nosso crescimento foi de 5,6 vezes nessas duas décadas, mais de três vezes o crescimento mundial que foi de apenas 1,7 vezes! Nas duas figuras observa-se que houve nítida inclinação nas curvas de crescimento na última década. Esses resultados são os frutos mais visíveis da decisão do Brasil em 1986, quando da criação do MCT, de investir substancialmente na formação de recursos humanos, especialmente de novos doutores. Sabidamente, o desempenho da ciência brasileira guarda correlação direta com nosso sistema de pós-graduação.

A tabela 1 ilustra os dados comparativos da produção brasileira juntamente com os 30 outros países mais produtivos no ranking mundial nos anos de 1981 e 2001. Vale destacar que em 1981 o Brasil, com uma produção de 1.887 artigos correspondendo a um índice de $0,44 \%$ da produção mundial, ocupava a 27ạ posição no ranking global da C\&T. Já em 2001 com um total de 10.555 artigos, equivalendo a 1,44\% do total mundial, o Brasil subiu nove pontos nessa escala, passando a ocupar a 18a posição. Nesta escalada, foram ultrapassados 13 países, entre os quais muitos com longa tradição científica: África do Sul, Áustria, Bélgica, Dinamarca, Escócia, Finlândia, Hungria, Israel, Noruega, Nova Zelândia, Polônia, Tchecoslováquia/República Tcheca e Ucrânia. Destaque-se que todos estes países tiveram também crescimento significativo na sua produção científica no período (média de 2,2 vezes), um índice 30\% superior à expansão da produção mundial. Nesse período, fomos ultrapassados pelos três países com o mais destacado crescimento mundial: China (cresceu 18 vezes), Coréia do Sul (cresceu 64 vezes) e Taiwan (cresceu 21 vezes). Já com referência aos países que estavam situados à frente do Brasil no ranking de 1981, vale destacar que para quase todos esses países (26 em 30 ), foi substancialmente reduzida a diferença do índice médio de produção relativamente ao Brasil: média dos países de 8,3 para 4,1 vezes para os dados da atual produção brasileira. Tal redução foi observada para todos os países do ranking de 1981, sendo as mais expressivas as relativas à Índia (de 7,0 para 1,6 ou seja 4,4 vezes) e aos EUA (de 91,2 para 23,7 isto é de 3,8 vezes). Em relação à produção mundial da base

\section{Figura 2}

Crescimento da produção científica brasileira em relação ao mundo.

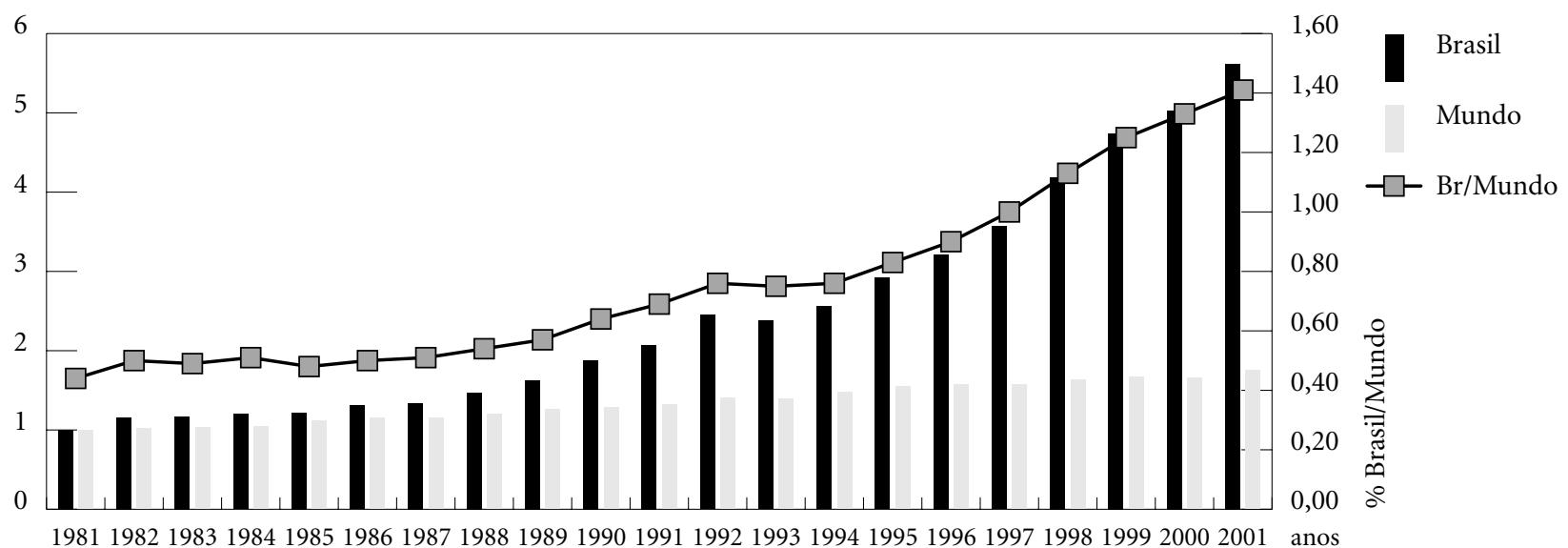

Fonte: Science Indicators - (ISI) / CD-Room - 2001 e Web of Science - (ISI) 
Tabela 1

Ranking dos 30 países com maior produção científica nos anos 1981 e 2001. Todas as áreas.

\begin{tabular}{|c|c|c|c|c|c|c|c|c|c|c|c|}
\hline \multirow[t]{2}{*}{ No } & \multirow[t]{2}{*}{ Países } & \multicolumn{3}{|c|}{ Artigos 1981} & \multirow[t]{2}{*}{ No } & \multirow[t]{2}{*}{ Países } & \multicolumn{3}{|c|}{ Artigos 2001} & \multirow{2}{*}{$\begin{array}{l}\text { Índice } \\
\text { de Cres- } \\
\text { cimento } \\
1981-2001\end{array}$} & \multirow{2}{*}{$\begin{array}{l}\text { Redução } \\
\text { da Dife- } \\
\text { rença } \\
\text { (A)/(B) } \\
\text { (Vezes) }\end{array}$} \\
\hline & & $\begin{array}{c}\text { Artigos } \\
n^{\circ}\end{array}$ & $\begin{array}{c}\% \\
\text { Mundo }\end{array}$ & $\begin{array}{c}\text { Relação ao } \\
\text { Brasil (A) }\end{array}$ & & & $\begin{array}{c}\text { Artigos } \\
\mathrm{n}^{\circ}\end{array}$ & $\begin{array}{c}\% \\
\text { Mundo }\end{array}$ & $\begin{array}{c}\text { Relação ao } \\
\text { Brasil (B) }\end{array}$ & & \\
\hline 1 & EUA & 171.997 & 40,1 & 91,2 & 1 & EUA & 250.128 & 34,1 & 23,7 & 1,5 & 3,9 \\
\hline 2 & Alemanha & 32.847 & 7,7 & 17,4 & 2 & Japão & 70.574 & 9,6 & 6,7 & 2,6 & 2,1 \\
\hline 3 & Inglaterra & 32.200 & 7,5 & 17,1 & 3 & Alemanha & 64.960 & 8,9 & 6,2 & 2,0 & 2,8 \\
\hline 4 & Japão & 26.725 & 6,2 & 14,2 & 4 & Inglaterra & 57.846 & 7,9 & 5,5 & 1,8 & 3,1 \\
\hline 5 & França & 22.371 & 5,2 & 11,9 & 5 & França & 46.435 & 6,3 & 4,4 & 2,1 & 2,7 \\
\hline 6 & Canadá & 19.372 & 4,5 & 10,3 & 6 & Canadá & 32.192 & 4,4 & 3,1 & 1,7 & 3,4 \\
\hline 7 & Índia & 13.288 & 3,1 & 7,0 & 7 & Itália & 31.436 & 4,3 & 3,0 & 3,4 & 1,7 \\
\hline 8 & Austrália & 10.352 & 2,4 & 5,5 & 8 & China & 29.381 & 4,0 & 2,8 & 17,9 & 0,3 \\
\hline 9 & Itália & 9.343 & 2,2 & 5,0 & 9 & Rússia & 23.265 & 3,2 & 2,2 & - & - \\
\hline 10 & Holanda & 7.143 & 1,7 & 3,8 & 10 & Espanha & 22.220 & 3,0 & 2,1 & 6,6 & 0,9 \\
\hline 11 & Suécia & 6.798 & 1,6 & 3,6 & 11 & Austrália & 21.054 & 2,9 & 2,0 & 2,0 & 2,8 \\
\hline 12 & Suíça & 6.082 & 1,4 & 3,2 & 12 & Holanda & 18.790 & 2,6 & 1,8 & 2,6 & 2,1 \\
\hline 13 & Israel & 4.866 & 1,1 & 2,6 & 13 & Índia & 16.623 & 2,3 & 1,6 & 1,3 & 4,5 \\
\hline 14 & Escócia & 4.492 & 1,1 & 2,4 & 14 & Suécia & 15.301 & 2,1 & 1,5 & 2,3 & 2,5 \\
\hline 15 & Polônia & 4.527 & 1,1 & 2,4 & 15 & Coréia do Sul & 14.641 & 2,0 & 1,4 & 63,7 & 0,1 \\
\hline 16 & Ucrânia & 4.263 & 1,0 & 2,3 & 16 & Suíça & 13.429 & 1,8 & 1,3 & 2,2 & 2,5 \\
\hline 17 & Bélgica & 4.201 & 1,0 & 2,2 & 17 & Taiwan & 10.635 & 1,5 & 1,0 & 20,6 & 0,3 \\
\hline 18 & Tchecoslováquia & 3.970 & 0,9 & 2,1 & 18 & Brasil & 10.555 & 1,4 & 1,0 & 5,6 & 1,0 \\
\hline 19 & Dinamarca & 3.827 & 0,9 & 2,0 & 19 & Bélgica & 9.909 & 1,4 & 0,9 & 2,4 & 2,3 \\
\hline 20 & Espanha & 3.372 & 0,8 & 1,8 & 20 & Polônia & 9.764 & 1,3 & 0,9 & 2,2 & 2,6 \\
\hline 21 & Finlândia & 2.579 & 0,6 & 1,4 & 21 & Israel & 9.323 & 1,3 & 0,9 & 1,9 & 2,9 \\
\hline 22 & Áustria & 2.701 & 0,6 & 1,4 & 22 & Escócia & 9.127 & 1,2 & 0,9 & 2,0 & 2,8 \\
\hline 23 & Hungria & 2.546 & 0,6 & 1,4 & 23 & Dinamarca & 7.752 & 1,1 & 0,7 & 2,0 & 2,8 \\
\hline 24 & Noruega & 2.282 & 0,5 & 1,2 & 24 & Finlândia & 7.393 & 1,0 & 0,7 & 2,9 & 2,0 \\
\hline 25 & África do Sul & 2.190 & 0,5 & 1,2 & 25 & Áustria & 7.331 & 1,0 & 0,7 & 2,7 & 2,1 \\
\hline 26 & Nova Zelândia & 2.169 & 0,5 & 1,2 & 26 & Turquia & 6.000 & 0,8 & 0,6 & 18,6 & 0,3 \\
\hline 27 & Brasil & 1.887 & 0,4 & 1,0 & 27 & Grécia & 5.240 & 0,7 & 0,5 & 5,6 & 1,0 \\
\hline 28 & China & 1.646 & 0,4 & 0,9 & 28 & Noruega & 4.976 & 0,7 & 0,5 & 2,2 & 2,4 \\
\hline 29 & País de Gales & 1.397 & 0,3 & 0,7 & 29 & México & 4.948 & 0,7 & 0,5 & 5,5 & 1,0 \\
\hline 30 & Egito & 1.264 & 0,3 & 0,7 & 30 & $\begin{array}{l}\text { República } \\
\text { Tcheca }\end{array}$ & 4.297 & 0,6 & 0,4 & 1,1 & 5,3 \\
\hline \multicolumn{2}{|c|}{ Subtotal } & 412.697 & 90,9 & 218,7 & \multicolumn{2}{|c|}{ Subtotal } & 835.525 & 92,2 & 79,2 & 2,0 & 2,8 \\
\hline \multicolumn{2}{|c|}{ Outros 145 países } & 41.455 & 9,1 & 22,0 & \multicolumn{2}{|c|}{ Outros 145 países } & 70.530 & 7,8 & 6,7 & 1,7 & 3,3 \\
\hline \multicolumn{2}{|c|}{ Total Mundial } & 454.152 & 100,0 & 240,7 & & 906.055 & 100,0 & 85,8 & 2,0 & 2,8 \\
\hline \multirow{2}{*}{\multicolumn{2}{|c|}{$\begin{array}{l}\text { Total Base Standard } \\
\text { Dupla Contagem \% }\end{array}$}} & 429.184 & - & 227,4 & \multicolumn{2}{|c|}{$\begin{array}{l}\text { Iotal Mundial } \\
\text { Total Base Standard }\end{array}$} & 734.248 & - & 69,6 & 1,7 & 3,3 \\
\hline & & 5,8 & - & - & \multicolumn{2}{|c|}{$\begin{array}{l}\text { Total Base Standard } \\
\text { Dupla Contagem \% }\end{array}$} & 23,4 & - & - & - & - \\
\hline
\end{tabular}

Fonte: Science Indicators 2001, formatado em CD-Rom. Institute for Scientific Information (ISI), EUA. Dados da Base Standard.

de dados Standard do ISI, a diferença do total de publicações em relação ao Brasil caiu de 227,4 para 69,6 vezes, uma diferença reduzida em 3,3 vezes (Tabela 1 ).

Com esse desempenho, o Brasil passou a contribuir com significativa parcela do total mundial dos trabalhos completos publicados em revistas de circulação internacional indexadas no ISI e assumiu posição destacada no rank- ing da produção científica mundial. No conjunto, os dados permitiram incluir o Brasil entre os 18 países mais destacados como geradores de novos conhecimentos. Excluída a participação dos EUA, que respondem atualmente por $34 \%$ da produção de todos os países, a diferença média da posição do Brasil em relação aos demais 16 países à sua frente em 2001 cai para 2,9 vezes. Isto permite antever que se não 
vierem a ocorrer limitações da sistemática de fomento à $\mathrm{C} \& \mathrm{~T}$ e mantido o ritmo atual de crescimento da produção científica brasileira, será possível superar na próxima década vários dos países concorrentes ainda situados à nossa frente, inserindo o Brasil no seleto grupo dos dez países cientificamente mais desenvolvidos que são os maiores produtores de conhecimentos novos no mundo! Afora nossos êxitos na música popular e no futebol, o desempenho do Brasil no campo científico está consubstanciado em parâmetros quali-quantitativos únicos de difícil equiparação com qualquer outro segmento do nosso espectro de atividades destacadas e presentes no competitivo ambiente internacional. Infelizmente, como mostrado recentemente nos dados do PISA 2000 (Programa Internacional de Avaliação de Alunos, OCDE, 2000) essa posição é totalmente inversa no campo da educação fundamental, especialmente no que concerne ao ensino de matemática e ciências, em que o desempenho do Brasil é notoriamente deficitário e alarmante. Este é, seguramente, o maior desafio a ser vencido pelo Brasil nos próximos anos de modo a conciliar um ensino qualificado com a preparação das novas gerações para manter o ritmo de capacitação científica necessária para permitir avanços do nosso desempenho em C\&T. Como visto acima, juntas, educação e C\&T, são instrumentos únicos, capazes de propiciar o desenvolvimento sustentável na exploração de nossas potencialidades naturais para permitir o pleno desenvolvimento econômico-social do País.

\section{Indicadores qualitativos}

Neste mesmo período (1981-2001) cresceu, igualmente, a qualificação de nossas publicações. Como se verifica na tabela 2, entre o primeiro qüinqüênio (1981-1985) e o último (1997-2001) a ciência brasileira apresentou, em relação aos parâmetros mundiais, destaque significativo de crescimento em todos os indicadores qualitativos analisados: total de artigos citados e seu percentual; o total de citações e o impacto dessas citações. Os quatro parâmetros em análise se baseiam nos dados de citações de artigos publicados e, de um modo geral, o número de artigos citados e o total de citações acompanham o número de trabalhos publicados. Todavia, no conjunto, os indicadores qualitativos mais duros (percentual de artigos citados e índice de impacto) expressam sobremodo o grau de aceitação das publicações pela comunidade científica mundial e, portanto, atribuem maior índice de qualificação a tais publicações. O índice de impacto, que representa a razão entre o total de citações e o número de publicações, expressa a qualificação da produção científica, porque elimina o componente quantitativo representado pelo número total de artigos publicados. Assim, não é raro ocorrer situações de países e de áreas específicas onde há menor número de publicações com elevado número de citações.

Os dados da tabela 2 indicam que o crescimento brasileiro mais expressivo ocorreu nos parâmetros número de artigos citados e total de citações que cresceram 5,3 e 6,9 vezes, respectivamente, acima, portanto, do crescimento do número de publicações que foi de 4 vezes. Nestes mesmos indicadores, os 18 países apresentaram crescimento médio de 2,1 e 2,7 vezes e todos os 175 países da base de dados, índices de 1,8 e 2,6 vezes apenas. A relevância desses avanços pode ser mais bem apreciada quando se sabe que os dados mundiais são fortemente influenciados (cerca de $85 \%$ ) pelo grupo dos 20 países mais produtivos do ranking mundial, bloco este no qual se insere hoje o Brasil (tabelas 1 e 2). Com 50,4\% de percentual de artigos citados e 2,3 no índice de impacto no qüinqüênio mais recente, o Brasil se situa, todavia, abaixo das referências mundiais $(59,0 \%$ e índice de 3,9$)$ e mais distante ainda dos 17 países à sua frente $(62,3 \%$ e impacto de 4,1$)$ nestes indicadores. Ainda assim, o Brasil apresentou crescimento positivo com índices $15 \%$ e $25 \%$ superiores aos parâmetros mundiais nestes dois indicadores e se situa à frente de fortes competidores quantitativos como: China, Rússia, Índia, Coréia do Sul e Taiwan (Tabela 2). Todavia, apesar dos avanços registrados pelo Brasil no período, níveis baixos nestes indicadores impõem preocupação com o futuro da nossa ciência, pois que constitui grande desafio ultrapassar os níveis atuais de desempenho nos parâmetros qualitativos que caracterizam a ciência contemporânea, posto que tais indicadores são uma garantia científica para assegurar avanços na inovação tecnológica.

\section{Contribuição das grandes áreas na produção científica brasileira}

O desempenho científico brasileiro não apresenta a mesma distribuição mostrada pelos países mais desenvolvidos (Tabela 3). No desempenho apresentado nesses 40 anos de ati- 
Tabela 2

Indicadores de desempenho quali-quantitativo da ciência brasileira nos qüinqüênios 1981-1985 e 1997-2001.

Comparação com os países à frente do Brasil no ranking mundial. Dados de todas as áreas.

\begin{tabular}{|c|c|c|c|c|c|c|c|c|c|c|c|c|c|c|c|}
\hline \multirow{2}{*}{$\begin{array}{l}\text { Países } \\
\text { Base: Ranking } \\
\text { Mundial 2001* }\end{array}$} & \multicolumn{3}{|c|}{ Total de Artigos } & \multicolumn{3}{|c|}{ Artigos Citados } & \multicolumn{3}{|c|}{$\%$ Artigos Citados } & \multicolumn{3}{|c|}{ Total de Citações } & \multicolumn{3}{|c|}{ Impacto } \\
\hline & $\begin{array}{c}1981-85 \\
\text { (A) }\end{array}$ & $\begin{array}{l}\text { 1997-01 } \\
\text { (B) }\end{array}$ & $(\mathrm{B}) /(\mathrm{A})$ & $\begin{array}{c}1981-85 \\
\text { (A) }\end{array}$ & $\begin{array}{l}\text { 1997-01 } \\
\text { (B) }\end{array}$ & (B)/(A) & $\begin{array}{c}1981-85 \\
(\mathrm{~A})\end{array}$ & $\begin{array}{l}\text { 1997-01 } \\
\text { (B) }\end{array}$ & $(\mathrm{B}) /(\mathrm{A})$ & $\begin{array}{c}1981-85 \\
\text { (A) }\end{array}$ & $\begin{array}{c}\text { 1997-01 } \\
\text { (B) }\end{array}$ & $(\mathrm{B}) /(\mathrm{A})$ & $\begin{array}{l}\text { 1981-85 } \\
\text { (A) }\end{array}$ & $\begin{array}{l}\text { 1997-01 } \\
\text { (B) }\end{array}$ & $(\mathrm{B}) /(\mathrm{A})$ \\
\hline 1. EUA & 890.805 & 1.226 .946 & 1,4 & 514.204 & 800.477 & 1,6 & 57,7 & 65,2 & 1,1 & 3.473 .996 & 7.283 .809 & 2,1 & 3,9 & 5,9 & 1,5 \\
\hline 2. Japão & 148.037 & 336.162 & 2,3 & 82.427 & 198.732 & 2,4 & 55,7 & 59,1 & 1,1 & 374.572 & 1.239 .503 & 3,3 & 2,5 & 3,7 & 1,5 \\
\hline 3. Alemanha & 169.732 & 312.381 & 1,8 & 88.913 & 196.162 & 2,2 & 52,4 & 62,8 & 1,2 & 465.151 & 1.476 .523 & 3,2 & 2,7 & 4,7 & 1,7 \\
\hline 4. Inglaterra & 168.014 & 281.991 & 1,7 & 99.259 & 180.985 & 1,8 & 59,1 & 64,2 & 1,1 & 590.005 & 1.460 .532 & 2,5 & 3,5 & 5,2 & 1,5 \\
\hline 5. França & 114.488 & 225.663 & 2,0 & 59.698 & 139.414 & 2,3 & 52,1 & 61,8 & 1,2 & 316.284 & 1.014 .457 & 3,2 & 2,8 & 4,5 & 1,6 \\
\hline 6. Canadá & 104.980 & 160.576 & 1,5 & 58.318 & 101.969 & 1,8 & 55,6 & 63,5 & 1.14 & 297.813 & 779.242 & 2,6 & 2,8 & 4,9 & 1,8 \\
\hline 7. Itália & 53.249 & 145.932 & 2,7 & 27.481 & 90.488 & 3,3 & 51,6 & 62,0 & 1,2 & 131.840 & 640.894 & 4,9 & 2,5 & 4,4 & 1,8 \\
\hline 8. China & 14.127 & 114.894 & 8,1 & 3.881 & 52.374 & 13,5 & 27,5 & 45,6 & 1,7 & 12.047 & 211.491 & 17,6 & 0,9 & 1,8 & 2,0 \\
\hline 9. Rússia & - & 122.712 & - & - & 48.409 & - & - & 39,5 & - & - & 214.050 & - & - & 1,7 & - \\
\hline 10. Espanha & 21.753 & 101.316 & 4,7 & 8.393 & 60.758 & 7,3 & 38,6 & 60,0 & 1,6 & 30.607 & 366.576 & 12,0 & 1,4 & 3,6 & 2,6 \\
\hline 11. Austrália & 52.832 & 100.920 & 1,9 & 30.190 & 100.920 & 3,3 & 57,1 & 62,2 & 1,1 & 146.175 & 410.945 & 2,8 & 2,8 & 4,1 & 1,5 \\
\hline 12. Holanda & 40.257 & 91.199 & 2,3 & 24.321 & 61.488 & 2,5 & 60,4 & 67,4 & 1,1 & 141.951 & 505.489 & 3,6 & 3,5 & 5,5 & 1,6 \\
\hline 13. Índia & 64.341 & 76.970 & 1,2 & 21.902 & 33.428 & 1,5 & 34,0 & 43,4 & 1,3 & 55.408 & 122.043 & 2,2 & 0,9 & 1,6 & 1,8 \\
\hline 14. Suécia & 38.374 & 72.436 & 1,9 & 23.372 & 48.587 & 2,1 & 60,9 & 67,1 & 1,1 & 144.231 & 366.029 & 2,5 & 3,8 & 5,1 & 1,3 \\
\hline 15. Coréia do Sul & 1.880 & 55.329 & 29,4 & 811 & 27.146 & 33,5 & 43,1 & 49,1 & 1,1 & 2.641 & 118.910 & 45,0 & 1,4 & 2,2 & 1,6 \\
\hline 16. Suíça & 32.210 & 66.051 & 2,1 & 19.020 & 44.577 & 2,3 & 59,1 & 67,5 & 1,1 & 145.767 & 438.172 & 3,0 & 4,5 & 6,6 & 1,5 \\
\hline 17. Tawain & 3.450 & 45.204 & 13,1 & 1.361 & 22.745 & 16,7 & 39,5 & 50,3 & 1,3 & 4.748 & 96.552 & 20,3 & 1,4 & 2,1 & 1,5 \\
\hline 18. Brasil & 10.856 & 43.692 & 4,0 & 4.164 & 21.998 & 5,3 & 38,4 & 50,4 & 1,3 & 14.345 & 98.692 & 6,9 & 1,3 & 2,3 & 1,8 \\
\hline $\begin{array}{l}\text { Dados dos } \\
18 \text { países }\end{array}$ & 1.929 .385 & 3.580 .374 & 1,9 & 1.067 .715 & 2.230 .657 & 2,1 & 55,3 & 62,3 & 1,2 & 6.347 .581 & 16.843 .909 & 2,7 & 2,4 & 3,9 & 1,6 \\
\hline $\begin{array}{l}\text { Mundo } \\
\text { (175 países) }\end{array}$ & 2.246 .842 & 3.545 .674 & 1,6 & 1.164 .314 & 2.091 .948 & 1,8 & 51,8 & 58,0 & 1,1 & 6.499 .225 & 16.970 .827 & 2,6 & 2,9 & 4,1 & 1,4 \\
\hline
\end{tabular}

* Ver ranking do ano 2001 na tabela 1.

** Inclui dupla contagem de cerca de $16 \%$ do total de artigos entre países e em relação ao total mundial.

Fonte: Science Indicators 2001. Base de acesso Standard. Institute for Scientific Information (ISI), EUA. 
Tabela 3

Produção científica das grandes áreas no Brasil e no mundo: quinqüênio 1997-2001.

\begin{tabular}{|c|c|c|c|c|c|c|c|c|}
\hline \multirow{4}{*}{\multicolumn{2}{|c|}{$\begin{array}{l}\text { Grandes Áreas } \\
\text { Ranking Mundial no qüinqüênio: } \\
\text { 1997-2001 } \\
\text { Ordem Áreas }\end{array}$}} & \multicolumn{5}{|c|}{ Base de Dados: Standard } & \multirow{2}{*}{\multicolumn{2}{|c|}{$\begin{array}{c}\text { Base de Dados: Deluxe } \\
\text { Brasil }\end{array}$}} \\
\hline & & \multicolumn{2}{|c|}{ Mundo } & \multicolumn{3}{|c|}{ Brasil } & & \\
\hline & & Artigos & \% Área & Artigos & \% Contribuição & $\%$ Brasil & Artigos & $\%$ Brasil \\
\hline & & & no Mundo & & $\begin{array}{c}\text { do Brasil } \\
\text { na Área }\end{array}$ & & & \\
\hline 1 & Medicina & 850.060 & 23,4 & 7.365 & 0,9 & 16,9 & 9.724 & 22,1 \\
\hline 2 & Ciências biomédicas* & 630.796 & 17,4 & 8.366 & 1,1 & 19,1 & 8.366 & 19,0 \\
\hline 3 & Química & 490.112 & 13,5 & 6.018 & 1,2 & 13,8 & 6.714 & 15,3 \\
\hline 4 & Física & 439.922 & 12,1 & 8.736 & 2,0 & 20,0 & 8.928 & 20,3 \\
\hline 5 & Ciências humanas e sociais* & 385.562 & 10,6 & 1.733 & 0,5 & 3,9 & 1.733 & 3,9 \\
\hline 6 & Engenharias & 264.523 & 7,3 & 2.503 & 1,0 & 5,7 & 2.503 & 5,7 \\
\hline 7 & $\begin{array}{l}\text { Pesquisa e produção } \\
\text { vegetal e animal }\end{array}$ & 219.468 & 6,0 & 3.822 & 1,7 & 8,7 & 4.062 & 9,2 \\
\hline 8 & Ciências biológicas* & 201.608 & 5,5 & 2.260 & 1,7 & 5,2 & 2.260 & 5,1 \\
\hline 9 & Ciência dos materiais & 131.770 & 3,6 & 1.477 & 1,1 & 3,4 & 1.477 & 3,4 \\
\hline 10 & Geociências & 99.236 & 2,7 & 1.071 & 1,1 & 2,5 & 1.072 & 2,4 \\
\hline 11 & $\begin{array}{l}\text { Agronomia e ciências } \\
\text { agrícolas }\end{array}$ & 82.659 & 2,3 & 2.288 & 2,8 & 5,2 & 2.288 & 5,2 \\
\hline 12 & Matemática & 62.922 & 1,7 & 876 & 1,4 & 2,0 & 876 & 2,0 \\
\hline 13 & Multidisciplinar & 50.407 & 1,4 & 404 & 0,8 & 0,9 & 404 & 0,9 \\
\hline 14 & Ciências espaciais & 44.298 & 1,2 & 857 & 1,9 & 2,0 & 857 & 1,9 \\
\hline 15 & Ciências da computação & 42.007 & 1,2 & 269 & 0,6 & 0,6 & 269 & 0,6 \\
\hline Total das & as áreas (A) & 3.995 .350 & 108,9 & 48.045 & 1,3 & 109,9 & 51.533 & 117,0 \\
\hline Total da & base de dados (B) & 3.545 .674 & 100,0 & 43.692 & 1,2 & 100,0 & 43.963 & 100,0 \\
\hline Dupla ce & contagem: (A)/(B) \% & 12,7 & 8,9 & 9,9 & 10,0 & 9,9 & 17,2 & 17,0 \\
\hline
\end{tabular}

* Somatório das subáreas extraídas da Base de dados Deluxe

Fonte: Science Indicators 2001. Bases de dados Standard e Deluxe. ISI.

vidades mais expressivas do Brasil em C\&T, constata-se, inequivocamente, maior destaque na produção das áreas mais tradicionais e, portanto, mais capacitadas em recursos humanos do nosso sistema de C\&T, a saber: física, medicina (com suas 30 subáreas), ciências biomédicas (bioquímica e biofísica, microbiologia, farmacologia, neurociências, biologia celular e do desenvolvimento, fisiologia e imunologia) e química que juntas produzem cerca de $70 \%$ da produção nacional. De fato, os pesquisadores dessas áreas publicaram no qüinqüênio 30.485 artigos do total de 43.692 publicações brasileiras da tabela 3. Acrescidas de algumas subáreas das ciências agrárias, das engenharias e das ciências humanas e sociais, esse total chega a cerca de $90 \%$ do total da produção científica brasileira. Nossa produção apresenta ainda, nítida discrepância com a participação mundial relativa em várias áreas. Isto é particularmente notório na física, na pesquisa e produção vegetal e animal, na agronomia e nas ciências espaciais com a proporção interna da produção brasilei- ra muito acima dos índices mundiais e, inversamente, nas ciências humanas e sociais e nas ciências da computação, com a participação interna muito abaixo dos índices mundiais. Nos dados da tabela 3 observa-se, como mencionado anteriormente, maior dupla contagem na produção brasileira, especialmente nos dados da base Deluxe. Como se observa, a maior contribuição nessa dupla contagem $(17,2 \%)$ provém dos dados da área médica que apresenta uma dupla contagem de $32 \%$ na comparação das duas bases de dados. Isto se deve à sobreposição de periódicos identificados em mais de uma das 30 subáreas da medicina. Tanto na ciência mundial como na brasileira, o conjunto mais produtivo mostrado na tabela 3 inclui contribuição significativa das áreas médica e biomédica, que juntas representam $40 \%$ na produção mundial e $36 \%$ na brasileira. É propósito deste artigo analisar mais detalhadamente a contribuição dessas duas grandes áreas no contexto da pesquisa brasileira e sua comparação com os dados mundiais. 


\section{Desempenho científico das áreas médica e biomédica no Brasil}

\section{Pesquisa médica no Brasil}

A produção científica mundial da área médica representa cerca de um quarto da produção qualificada de todas as áreas nos 175 países que compõem as bases de dados do ISI. A tabela 4 lista os parâmetros quali-quantitativos dos 30 países cientificamente mais produtivos nesta área no qüinqüênio 1997-2001. Juntos, os 30 países respondem por cerca de $95 \%$ da produção mundial na pesquisa médica. Inicialmente, verifica-se que os primeiros sete países do ranking mundial de todas as áreas ocupam posições similares no ranking da produção em medicina. Todavia, comparativamente ao ranking da tabela 1 e dada à ênfase de suas produções científicas em medicina, verifica-se que Israel e Turquia e os países europeus (Holanda, Suíça, Bélgica, Escócia e Áustria) e, especialmente os escandinavos (Suécia, Finlândia e Dinamarca), ocupam posição muito mais destacada no ranking da tabela 4 . Conseqüentemente outros países (Rússia, China, Índia, Coréia do Sul, Taiwan e Brasil) passam a ocupar posições menos destacadas nesta tabela e que outros ocupantes da tabela 1 não estão presentes no ranking da produção em medicina (Polônia, México e República Tcheca), entrando em seus lugares Nova Zelândia, África do Sul e País de Gales.

No período 1997-2001, foram publicados pelos 175 países da base de dados Standard do ISI 850.060 artigos completos na medicina e suas subáreas para um total mundial de 3.545.674 artigos do conjunto de todas as áreas somadas. Excluída a destacada participação dos EUA $(37,6 \%)$, a contribuição de cada país para o volume total de artigos variou de $0,4 \%$ (País de Gales) a 9,1\% (Inglaterra, a segunda do ranking). No que concerne à participação interna na produção em cada país, a distribuição foi mais homogênea, já que à exceção da Rússia (3,3\%), Índia (9,8\%) e Coréia do Sul (12,5\%), em todos os demais países da tabela 3 a produção de artigos em medicina representou pelo menos $15 \%$ da sua produção total interna. O destaque ficou com a Turquia com cerca de $39 \%$ da sua produção sendo centralizada na pesquisa médica. Com esse desempenho, a Turquia (20a posição no ranking) se situa no nível do bloco dos países europeus que apresentam a mais forte tradição e desempenho em pesquisa em medicina: Itália, Holanda, Suécia, Bélgica, Finlândia, Áustria, Dinamarca e Noruega, todos com mais de $28 \%$ da sua produção científica originada na área médica. Com exceção da Noruega, todos esses países estão situados bem à frente da Turquia no ranking de produção. Quanto ao Brasil, a pesquisa em medicina com uma produção de 7.365 artigos no período ( $0,9 \%$ da área no mundo) ocupa a 23a posição no ranking mundial e a terceira na produção interna, representando $16,9 \%$ do total de artigos indexados do país na base Standard do ISI (tabelas 3 e 4). Como já mencionado, o percentual de contribuição mais elevado $(22,1 \%)$ visto na coluna da base Deluxe da tabela 3 se deve ao elevado índice de dupla contagem de artigos apresentado pela área médica.

A tabela 4 apresenta também o desempenho dos países na pesquisa médica quanto aos indicadores que qualificam essa produção científica. Ressalve-se que os quatro parâmetros em análise refletem as citações de artigos publicados, que são, como se sabe, mais bem definidos para períodos mais longos do que os cinco anos da tabela e mais distantes do que o recente qüinqüênio analisado. Todavia, como dado comparativo entre países entende-se que tais circunstâncias estariam afetando o conjunto e não apenas um determinado país. Como já mencionado, os parâmetros número de artigos citados e total de citações usualmente acompanham o total de artigos publicados e, por isso mesmo introduzem pequenas variações no ranking dos 30 países da tabela. Todavia, com relação aos indicadores percentual de artigos citados e impacto das publicações da área, pode-se observar na tabela, variações surpreendentes nas posições relativas dos países no ranking (números entre parêntesis nas colunas da tabela). Como tais indicadores expressam a internacionalização e o grau de aceitação de tais artigos pela comunidade médico-científica mundial e atribuem qualificação às respectivas publicações, verifica-se expressiva presença de vários países europeus que apresentam maior destaque nesses indicadores. Nos índices mais elevados (dez países) no percentual de artigos citados, aparecem, na ordem: Holanda, com $70,2 \%$ dos artigos citados, seguida da Dinamarca $(69,9 \%)$, Suécia $(69,5 \%)$, Finlândia $(69,3 \%)$, Noruega (68,4\%), Canadá (67,3\%), EUA (67\%), Escócia $(66,6 \%)$, Inglaterra $(65,5 \%)$ e Nova Zelândia $(65,3 \%)$. O percentual médio neste indicador no período para os 30 países da tabela foi de $63,4 \%$. Neste grupo, cinco países (Fin- 
Tabela 4

Medicina: produção científica 1997-2001. Comparação do desempenho quali-quantitativo entre 30 países mais produtivos da área no ranking mundial no período.

\begin{tabular}{|c|c|c|c|c|c|c|c|}
\hline \multirow[t]{2}{*}{ Países no Ranking 1997-2001 } & \multicolumn{3}{|c|}{ Produção Científica } & \multirow{2}{*}{$\begin{array}{c}\text { Artigos } \\
\text { Citados } \\
\text { Número }^{*}\end{array}$} & \multirow{2}{*}{$\begin{array}{c}\text { Artigos } \\
\text { Citados } \\
\%^{\star}\end{array}$} & \multirow{2}{*}{$\begin{array}{c}\text { Total de } \\
\text { Citações } \\
\text { Número }^{*}\end{array}$} & \multirow{2}{*}{$\begin{array}{c}\text { Impacto } \\
\text { da Ârea } \\
\text { Índice }\end{array}$} \\
\hline & Artigos & $\begin{array}{c}\text { \% País no } \\
\text { Mundo }\end{array}$ & $\begin{array}{l}\text { \% Área } \\
\text { no País }\end{array}$ & & & & \\
\hline 1. EUA & 319.170 & 37,6 & 26,0 & $213.894(1)$ & $67,0(7)$ & $1.937 .706(1)$ & $6,1(4)$ \\
\hline 2. Inglaterra & 77.550 & 9,1 & 27,5 & $50.756(2)$ & $65,5(9)$ & 420.577 (2) & $5,4(10)$ \\
\hline 3. Alemanha & 74.929 & 8,8 & 24,0 & $44.274(4)$ & $59,1(18)$ & $320.829(3)$ & $4,3(18)$ \\
\hline 4. Japão & 74.391 & 8,7 & 22,1 & $44.333(3)$ & $59,6(17)$ & $265.442(4)$ & $3,6(21)$ \\
\hline 5. França & 49.798 & 5,9 & 22,1 & $28.817(5)$ & $57,9(20)$ & $227.214(5)$ & $4,6(16)$ \\
\hline 6. Itália & 40.804 & 4,8 & 28,0 & $25.850(6)$ & $63,4(13)$ & $206.661(7)$ & $5,1(12)$ \\
\hline 7. Canadá & 36.877 & 4,3 & 23,0 & $24.821(7)$ & $67,3(6)$ & $224.635(6)$ & $6,1(3)$ \\
\hline 8. Holanda & 27.795 & 3,3 & 30,5 & $19.517(8)$ & $70,2(1)$ & $176.702(8)$ & $6,4(1)$ \\
\hline 9. Austrália & 23.503 & 2,8 & 23,3 & $15.252(10)$ & $64,9(11)$ & $113.402(10)$ & $4,8(15)$ \\
\hline 10. Suécia & 22.543 & 2,7 & 31,1 & $15.655(9)$ & $69,5(3)$ & $124.253(9)$ & $5,5(8)$ \\
\hline 11. Espanha & 21.027 & 2,5 & 20,8 & $12.026(11)$ & $57,2(21)$ & $81.341(12)$ & $3,9(20)$ \\
\hline 12. Suíça & 17.026 & 2,0 & 25,8 & $10.742(12)$ & $63,1(15)$ & $92.847(11)$ & $5,5(9)$ \\
\hline 13. Bélgica & 13.283 & 1,6 & 28,2 & $8.619(13)$ & $64,9(12)$ & $76.599(13)$ & $5,8(7)$ \\
\hline 14. Israel & 11.708 & 1,4 & 26,2 & $6.782(18)$ & 57,9 (19) & $47.051(18)$ & 4,0 (19) \\
\hline 15. Finlândia & 11.501 & 1,4 & 33,5 & $7.969(14)$ & $69,3(4)$ & $71.475(14)$ & $6,2(2)$ \\
\hline 16. Escócia & 11.301 & 1,3 & 25,3 & $7.521(15)$ & $66,6(8)$ & $65.706(15)$ & $5,8(6)$ \\
\hline 17. Áustria & 11.282 & 1,3 & 34,1 & $6.822(17)$ & $60,5(16)$ & $48.742(17)$ & $4,3(17)$ \\
\hline 18. Dinamarca & 10.523 & 1,2 & 28,5 & $7.354(16)$ & $69,9(2)$ & $62.032(16)$ & $5,9(5)$ \\
\hline 19. China & 10.172 & 1,2 & 8,9 & $5.192(19)$ & $51,0(26)$ & $30.335(20)$ & $3,0(23)$ \\
\hline 20. Turquia & 9.002 & 1,1 & 38,9 & 3.797 (23) & $42,2(29)$ & $12.365(27)$ & $1,4(30)$ \\
\hline 21. Taiwan & 8.642 & 1,0 & 19,1 & $4.767(20)$ & $55,2(24)$ & $23.530(21)$ & $2,7(26)$ \\
\hline 22. Índia & 7.562 & 0,9 & 9,8 & $3.624(24)$ & $47,9(28)$ & $11.750(28)$ & $1,7(28)$ \\
\hline 23. Brasil & 7.365 & 0,9 & 16,9 & $3.885(22)$ & $52,8(25)$ & $20.936(23)$ & $2,8(25)$ \\
\hline 24. Coréia do Sul & 6.922 & 0,8 & 12,5 & $3.396(25)$ & $49,1(27)$ & $17.520(29)$ & $2,5(27)$ \\
\hline 25. Noruega & 6.827 & 0,8 & 28,9 & $4.671(21)$ & $68,4(5)$ & 36.809 (19) & $5,4(11)$ \\
\hline 26. Grécia & 5.696 & 0,7 & 25,8 & $3.158(26)$ & $55,4(23)$ & $16.282(25)$ & $2,9(24)$ \\
\hline 27. Nova Zelândia & 4.593 & 0,5 & 22,0 & $3.000(27)$ & $65,3(10)$ & $22.222(22)$ & $4,8(14)$ \\
\hline 28. Rússia & 4.081 & 0,5 & 3,3 & $981(30)$ & $24,0(30)$ & $6.611(30)$ & $1,6(29)$ \\
\hline 29. África do Sul & 3.803 & 0,4 & 21,7 & $2.140(29)$ & $56,3(22)$ & $12.706(26)$ & $3,3(22)$ \\
\hline 30. País de Gales & 3.497 & 0,4 & 23,8 & $2.207(28)$ & $63,1(14)$ & $17.599(24)$ & $5,0(13)$ \\
\hline Dados da tabela & 933.173 & 94,6 & 23,7 & 591.822 & 63,4 & 4.791 .879 & 5,1 \\
\hline Outros 145 países & 52.786 & 5,4 & - & - & - & - & - \\
\hline Dados no mundo (A) & 985.959 & 100,0 & - & - & - & - & - \\
\hline Total base Deluxe (B) & 850.060 & - & 23,4 & 523.430 & 61,6 & 3.856 .287 & 4,5 \\
\hline Sobreposição A / B, \% & 16,0 & - & - & - & - & - & - \\
\hline Total Geral Mundo & 3.545 .674 & - & - & 2.104 .746 & 58,0 & 14.704 .538 & 4,1 \\
\hline
\end{tabular}

* Números entre parêntesis indicam posição dos 30 países no ranking do respectivo indicador.

Fonte: Science Indicators, 2001. Acesso Base Standard. ISI

lândia, Escócia, Dinamarca, Noruega e Nova Zelândia) e mais o País de Gales $(63,1 \%$ de artigos citados e 14o colocado no ranking qualitativo) ocupam posição menos destacada na produção total de artigos na área, indicando que as publicações médicas desses países, independente de seu número total, são referenciadas mundialmente de forma preferencial. Cabe destacar nesse aspecto a defasagem de posições ocupadas pelos seis primeiros colocados no ranking da produção (EUA, Japão, Inglaterra, Alemanha, França, Itália) e mais a Espanha que ocupam posições inferiores no ranking percentual de artigos citados. Tal defasagem (menor porcentagem de citações relativamente ao total de publicações) pode ser mais bem compreen- 
dida, para efeito de qualificar a produção científica, pelo indicador índice de impacto, que representa a razão entre o total de citações e o número de publicações. O índice médio mundial foi de 4,5 no período 1997-2001. Aqui verifica-se, novamente, o bom desempenho da Holanda $(6,4)$, Finlândia $(6,2)$, Dinamarca $(5,9)$, Escócia e Bélgica $(5,8)$, Suécia e Suíça $(5,5)$, além da recuperação de Canadá e EUA $(6,1)$.

O Brasil produziu no período 7.365 artigos, ocupando, portanto a 23a posição no ranking quantitativo da área médica. Com índices qualitativos de 52,8\% de artigos citados e 2,8 de índice de impacto na área médica, teve sua posição alterada nos dois rankings passando para a 25a posição. Apesar do distanciamento nos índices que separa o Brasil dos índices médios mundiais e sobretudo dos 22 países à sua frente, sendo portanto os mais avançados no ranking dos indicadores qualitativos, o desempenho do Brasil na pesquisa médica o situa à frente de fortes competidores como China, Índia, Coréia do Sul, Rússia e Turquia e no limite da competição com Taiwan, Grécia, África do Sul e Espanha. Constata-se, ademais, que nestes índices o Brasil apresentou incremento considerável nessas duas décadas: no qüinqüênio 1981-1985, tais índices eram de 37,5\% e 1,39, respectivamente. Vale registrar que um número reduzido de áreas no Brasil apresenta índices mais elevados destes indicadores, sendo as respectivas médias brasileiras no qüinqüênio de $50,4 \%$ e 2,3 para os dois indicadores. Destacam-se, neste aspecto, as ciências espaciais $(71,3 \%$ de citações e impacto de 5,3) e, como se verá adiante, várias subáreas das ciências biomédicas: imunologia $(68,9 \%$ e 4,3$)$; bioquímica e biofísica $(67,2 \%$ e 3,8$)$, neurociências $(65,1 \%$ e 4,1$)$; microbiologia $(60,1 \%$ e 3,2$)$ e biologia celular e do desenvolvimento $(60,0 \%$ e 3,0$)$. Não obstante, como se verá nas tabelas 6 e 7, várias subáreas da medicina apresentam estes índices em níveis muito mais elevados do que o apresentado pela grande área. Por outro lado, muitas subáreas da pesquisa médica brasileira apresentam níveis muito baixos nestes indicadores, confirmando que mesmo nesta área, uma das mais produtivas do Brasil, há elevado grau de heterogeneidade nas atividades de pesquisa o que se reflete no desempenho do conjunto da área médica.

A tabela 5 apresenta a participação das áreas, subáreas e campos de atuação da medicina no desempenho da pesquisa médica brasileira. A produção de artigos indexados no ISI no pe- ríodo 1997-2001 foi a base para a elaboração do ranking das subáreas apresentado na tabela. Como mencionado na metodologia, relembrase que a área de saúde coletiva foi adicionada às 30 subáreas da base Deluxe do ISI, perfazendo o total de 31 áreas, subáreas ou campos de pesquisa listados na tabela. Na média, a contribuição do conjunto na produção científica mundial da grande área $(0,9 \%)$ no período 1997 2001 é inferior à média da participação brasileira na produção global neste mesmo qüinqüênio $(1,2 \%)$. Todavia, diversas subáreas apresentam contribuição superior a esta média nacional: tópicos gerais em medicina, odontologia e cirurgia bucal $(2,76 \%)$; medicina ambiental e saúde pública (1,63\%); imunologia clínica e doenças infecciosas $(1,42 \%)$ e saúde pública $(1,28 \%)$. Novamente verifica-se que a contribuição quantitativa nem sempre implica desempenho qualitativo. Quanto a estes indicadores, as médias da área médica mostradas na tabela 5 (52,8\% de artigos citados e 3,1 de impacto das publicações) são superiores às médias brasileiras de todas as áreas (50,4\% e impacto de 2,3 ). Vale notar que há uma pequena diferença no índice de impacto da área médica obtido nos dois bancos de dados: 2,8 no acesso Standard (Tabela 4) e 3,1 no acesso Deluxe (Tabela 5). Como já comentado, isto se deve à mais elevada dupla contagem dos dados das subáreas da medicina apresentado no acesso Deluxe. No percentual de artigos citados os índices variaram de $22,7 \%$ a $71,6 \%$ com várias subáreas apresentando desempenho destacado, considerando-se a média mundial $(61,6 \%)$ : imunologia clínica, endocrinologia, hematologia, cardiologia, oncologia, medicina ambiental e saúde pública, reumatologia, oncogênese e câncer e medicina laboratorial. Num segundo grupo estão dez subáreas que se situam bem abaixo da média nacional: ortopedia e medicina esportiva $(22,7 \%)$, saúde pública $(29,2 \%)$, serviços em saúde $(33,4 \%)$, dermatologia $(36,4 \%)$, radiologia e medicina nuclear $(38,5 \%)$, odontologia e cirurgia bucal $(39,6 \%)$, cirurgia $(42,4 \%)$, otorrinolaringologia $(42,5 \%)$, oftalmologia $(45,5 \%)$ e pediatria $(46,8 \%)$. No que respeita ao impacto das publicações, os dois grupos acima apresentam situação similar quanto ao desempenho destacado para cima ou para baixo. Todavia, no segundo grupo incluem-se outras áreas com impacto inferior à média nacional. Já no grupo de melhor desempenho, destaque-se a inclusão da subárea medicina interna que apresentou índice de impacto excepcional $(17,6)$, 
Tabela 5

Produção científica do Brasil em áreas e subáreas da medicina. Indicadores quali-quantitativos no qüinqüênio 1997-2001.

\begin{tabular}{|c|c|c|c|c|c|c|c|}
\hline \multirow[t]{2}{*}{ No } & \multirow[t]{2}{*}{ Medicina: Áreas e Subáreas } & \multicolumn{2}{|c|}{ Artigos } & \multicolumn{2}{|c|}{ Artigos Citados } & \multicolumn{2}{|c|}{ Citações } \\
\hline & & Total & $\%$ Mundo* & Total & $\%$ & Total & $\begin{array}{l}\text { Índice de } \\
\text { Impacto }\end{array}$ \\
\hline 1 & Medicina, tópicos gerais & 2.167 & 2,8 & 1.083 & 50,0 & 5.658 & 2,6 \\
\hline 2 & Medicina, órgãos e sistemas & 770 & 0,7 & 455 & 59,1 & 2.103 & 2,7 \\
\hline 3 & Medicina, diagnóstico e tratamento & 611 & 0,7 & 331 & 54,2 & 1.615 & 2,6 \\
\hline 4 & Cardiologia e sistema respiratório & 531 & 0,7 & 317 & 59,7 & 2.225 & 4,2 \\
\hline 5 & Saúde pública & 514 & 1,3 & 150 & 29,2 & 342 & 0,7 \\
\hline 6 & Cardiologia e hematologia & 502 & 0,7 & 320 & 63,8 & 2.638 & 5,3 \\
\hline 7 & Odontologia e cirurgia bucal & 495 & 2,8 & 196 & 39,6 & 615 & 1,2 \\
\hline 8 & Imunologia clínica e doenças infecciosas & 416 & 1,4 & 298 & 71,6 & 2.132 & 5,1 \\
\hline 9 & Cirurgia & 368 & 0,8 & 156 & 42,4 & 416 & 1,1 \\
\hline 10 & Medicina ambiental e saúde pública & 354 & 1,6 & 222 & 62,7 & 1.058 & 3,0 \\
\hline 11 & Medicina laboratorial e tecnologia médica & 280 & 0,9 & 170 & 60,7 & 1.110 & 4,0 \\
\hline 12 & Pediatria & 248 & 0,7 & 116 & 46,8 & 473 & 1,9 \\
\hline 13 & Medicina da reprodução & 244 & 0,8 & 128 & 52,5 & 462 & 1,9 \\
\hline 14 & Urologia & 232 & 0,7 & 135 & 58,2 & 859 & 3,7 \\
\hline 15 & Neurologia & 202 & 0,5 & 119 & 58,9 & 969 & 4,8 \\
\hline 16 & Oncogênese e câncer & 193 & 0,3 & 118 & 61,1 & 666 & 3,5 \\
\hline 17 & Gastroenterologia e hepatologia & 176 & 0,6 & 97 & 55,1 & 468 & 2,7 \\
\hline 18 & Endocrinologia, metabolismo e nutrição & 174 & 0,9 & 117 & 67,2 & 1.029 & 5,9 \\
\hline 19 & Medicina interna geral & 133 & 0,2 & 74 & 55,6 & 2.340 & 17,6 \\
\hline 20 & Oncologia & 132 & 0,3 & 83 & 62,9 & 411 & 3,1 \\
\hline 21 & Oftalmologia & 132 & 0,7 & 60 & 45,5 & 193 & 1,5 \\
\hline 22 & Radiologia, medicina nuclear e por imagem & 130 & 0,3 & 50 & 38,5 & 206 & 1,6 \\
\hline 23 & Hematologia & 122 & 0,6 & 78 & 63,9 & 509 & 4,2 \\
\hline 24 & Otorrinolaringologia & 113 & 0,7 & 48 & 42,5 & 130 & 1,2 \\
\hline 25 & Anestesiologia e cuidados intensivos & 106 & 0,4 & 58 & 54,7 & 389 & 3,7 \\
\hline 26 & Dermatologia & 99 & 0,6 & 36 & 36,4 & 109 & 1,1 \\
\hline 27 & Reumatologia & 73 & 0,7 & 45 & 61,7 & 205 & 2,8 \\
\hline 28 & Farmacotoxicologia & 72 & 0,4 & 45 & 62,5 & 164 & 2,3 \\
\hline 29 & Psicologia clínica e psiquiatria & 70 & 0,4 & 38 & 54,3 & 230 & 3,3 \\
\hline 30 & Ortopedia e medicina esportiva & 53 & 0,2 & 12 & 22,7 & 50 & 0,9 \\
\hline 31 & Serviços em saúde & 12 & 0,1 & 4 & 33,4 & 5 & 0,4 \\
\hline \multicolumn{2}{|c|}{ Total das áreas e subáreas: Brasil } & 9.724 & 0,9 & 5.159 & 52,8 & 29.779 & 3,1 \\
\hline \multicolumn{2}{|c|}{ Total Mundial das Áreas/Subáreas } & 850.060 & $23,4^{\star *}$ & 523.430 & 61,6 & 3.856 .287 & 4,5 \\
\hline \multicolumn{2}{|r|}{ Total Geral Mundo (Base Deluxe) } & 3.630 .750 & 100,0 & 2.104 .746 & 58,0 & 14.704 .538 & 4,1 \\
\hline
\end{tabular}

* Refere-se à contribuição do Brasil na produção total da respectiva área.

** Refere-se ao percentual de publicações da área sobre a produção mundial em todas as áreas.

Fonte: Science Indicators 2001. Base de acesso Deluxe. Institute for Scientific Information (ISI), EUA.

na verdade o maior índice de todo o ranking mundial da área médica! (Tabelas 5 e 6).

Para melhor visualizar a situação qualitativa da produção científica brasileira na área médica, buscamos comparar nas tabelas 6 e 7 os dados do Brasil com os índices mundiais e com os dos seis países mais destacados nesses mesmos indicadores no qüinqüênio 1997-2001. A tabela 6 apresenta o percentual de artigos citados nas 31 subáreas da medicina pelo Brasil (listadas em ordem alfabética) em comparação com o mundo e com os seis países de melhor desempenho no indicador: Holanda, Finlândia, EUA, Canadá, Dinamarca e Suécia. Refletindo a aceitação mundial da qualidade da pesquisa médica feita nestes países, algumas subáreas apresentam os mais elevados índices de citação, destacando-se a pesquisa em oncogênese e oncologia, endocrinologia, cardiologia, hematologia, tópicos gerais em medicina, imunologia clínica, gastroenterologia, neurologia e psicologia clínica. Coincidentemente, a maioria dessas 
Tabela 6

Indicadores qualitativos da produção científica em áreas e subáreas da medicina.

Comparação Brasil, mundo e seis países mais destacados na área no qüinqüênio 1997-2001.

\begin{tabular}{|c|c|c|c|c|c|c|c|c|c|c|}
\hline \multirow[t]{2}{*}{ No } & \multirow{2}{*}{$\begin{array}{l}\text { Medicina: } \\
\text { Áreas e Subáreas }\end{array}$} & \multicolumn{9}{|c|}{$\%$ de Artigos Citados } \\
\hline & & Brasil & Mundo & Holanda & Finlândia & EUA & Canadá & Dinamarca & Suécia & $\begin{array}{l}\text { Média } \\
\text { seis países }\end{array}$ \\
\hline 1 & $\begin{array}{l}\text { Anestesiologia e cuidados } \\
\text { intensivos }\end{array}$ & 54,7 & 61,4 & 64,4 & 71,4 & 64,5 & 65,7 & 68,9 & 67,2 & 67,0 \\
\hline 2 & Cardiologia e hematologia & 63,8 & 72,2 & 77,6 & 78,1 & 74,3 & 74,3 & 76,9 & 76,2 & 76,2 \\
\hline 3 & $\begin{array}{l}\text { Cardiologia e sistema } \\
\text { respiratório }\end{array}$ & 59,7 & 64,0 & 73,4 & 72,1 & 69,5 & 70,6 & 70,3 & 70,5 & 71,1 \\
\hline 4 & Cirurgia & 42,4 & 53,1 & 58,6 & 64,2 & 62,3 & 53,8 & 61,1 & 59,9 & 60,0 \\
\hline 5 & Dermatologia & 36,4 & 57,5 & 66,9 & 73,2 & 61,5 & 65,6 & 69,1 & 68,7 & 67,5 \\
\hline 6 & $\begin{array}{l}\text { Endocrinologia, metabolismo } \\
\text { e nutrição }\end{array}$ & 67,2 & 74,0 & 76,8 & 75,7 & 76,8 & 77,6 & 77,9 & 75,9 & 76,8 \\
\hline 7 & Farmacotoxicologia & 62,5 & 65,9 & 68,7 & 73,5 & 65,4 & 68,8 & 70,3 & 70,2 & 69,5 \\
\hline 8 & $\begin{array}{l}\text { Gastroenterologia } \\
\text { e hepatologia }\end{array}$ & 55,1 & 66,5 & 70,5 & 73,6 & 71,5 & 69,9 & 77,3 & 75,8 & 73,1 \\
\hline 9 & Hematologia & 63,9 & 68,2 & 74,9 & 71,1 & 74,8 & 74,9 & 80,2 & 77,5 & 75,6 \\
\hline 10 & $\begin{array}{l}\text { Imunologia clínica } \\
\text { e doenças infecciosas }\end{array}$ & 71,6 & 68,4 & 74,4 & 71,7 & 73,1 & 74,2 & 72,3 & 74,8 & 73,4 \\
\hline 11 & $\begin{array}{l}\text { Medicina ambiental } \\
\text { e saúde pública }\end{array}$ & 62,7 & 65,0 & 71,8 & 66,4 & 69,5 & 68,8 & 71,1 & 67,9 & 69,3 \\
\hline 12 & Medicina da reprodução & 52,5 & 60,7 & 64,4 & 62,0 & 66,0 & 68,6 & 64,5 & 68,0 & 65,6 \\
\hline 13 & $\begin{array}{l}\text { Medicina, diagnóstico } \\
\text { e tratamento }\end{array}$ & 54,2 & 65,9 & 71,7 & 72,4 & 70,3 & 69,3 & 70,7 & 70,6 & 70,8 \\
\hline 14 & Medicina interna geral & 55,6 & 53,3 & 70,4 & 76,4 & 65,7 & 66,9 & 74,5 & 74,3 & 71,4 \\
\hline 15 & $\begin{array}{l}\text { Medicina laboratorial } \\
\text { e tecnologia médica }\end{array}$ & 60,7 & 65,7 & 76,2 & 72,8 & 68,7 & 68,9 & 66,2 & 69,3 & 70,4 \\
\hline 16 & Medicina, órgãos e sistemas & 59,1 & 66,2 & 71,9 & 65,3 & 67,0 & 69,4 & 69,5 & 70,1 & 68,9 \\
\hline 17 & Medicina, tópicos gerais & 50,0 & 67,7 & 77,1 & 75,0 & 74,4 & 74,0 & 72,2 & 74,6 & 74,6 \\
\hline 18 & Neurologia & 58,9 & 63,8 & 71,1 & 77,1 & 70,5 & 71,3 & 71,3 & 72,9 & 72,4 \\
\hline 19 & Odontologia e cirurgia bucal & 39,6 & 54,0 & 64,7 & 65,1 & 55,7 & 58,7 & 63,5 & 67,3 & 62,5 \\
\hline 20 & Oftalmologia & 45,5 & 55,0 & 63,2 & 65,1 & 59,7 & 58,5 & 64,4 & 63,4 & 62,4 \\
\hline 21 & Oncologia & 62,9 & 70,6 & 76,8 & 77,8 & 76,2 & 77,4 & 78,2 & 75,2 & 76,9 \\
\hline 22 & Oncogênese e câncer & 61,1 & 74,1 & 78,0 & 77,5 & 78,2 & 78,3 & 78,1 & 75,8 & 77,7 \\
\hline 23 & Ortopedia e medicina esportiva & 22,7 & 39,1 & 43,1 & 55,4 & 40,8 & 47,4 & 55,2 & 51,9 & 49,0 \\
\hline 24 & Otorrinolaringologia & 42,5 & 49,4 & 57,5 & 36,5 & 56,9 & 50,9 & 44,1 & 52,0 & 49,6 \\
\hline 25 & Pediatria & 46,8 & 53,8 & 63,6 & 68,4 & 58,1 & 60,4 & 67,6 & 67,8 & 64,3 \\
\hline 26 & Psicologia clínica e psiquiatria & 54,3 & 68,6 & 70,7 & 70,2 & 72,4 & 69,8 & 76,5 & 74,0 & 72,3 \\
\hline 27 & $\begin{array}{l}\text { Radiologia, medicina } \\
\text { nuclear e por imagem }\end{array}$ & 38,5 & 60,8 & 69,2 & 63,0 & 65,8 & 61,7 & 67,8 & 66,2 & 65,6 \\
\hline 28 & Reumatologia & 61,7 & 65,9 & 72,8 & 68,8 & 69,0 & 72,6 & 66,2 & 74,1 & 70,6 \\
\hline 29 & Saúde pública & 29,2 & 53,8 & 60,4 & 56,0 & 55,5 & 55,8 & 50,8 & 55,5 & 55,7 \\
\hline 30 & Serviços em saúde & 33,4 & 55,9 & 58,4 & 50,6 & 59,3 & 59,8 & 57,2 & 59,3 & 57,4 \\
\hline 31 & Urologia & 58,2 & 60,7 & 68,8 & 65,8 & 69,1 & 72,1 & 69,3 & 68,6 & 69,0 \\
\hline Mé & dia dos Países & 52,8 & 61,6 & 68,6 & 68,1 & 66,5 & 67,0 & 68,5 & 68,9 & 67,9 \\
\hline
\end{tabular}

Fonte: Science Indicators 2001. Base de acesso Deluxe. Institute for Scientific Information (ISI), EUA. 


\begin{tabular}{|c|c|c|c|c|c|c|c|c|c|c|}
\hline $\begin{array}{l}\text { Tab } \\
\text { Ind }\end{array}$ & $\begin{array}{l}\text { ela } 7 \\
\text { icadores qualitativos: índice de im } \\
\text { nparação Brasil, mundo e seis país }\end{array}$ & $\begin{array}{l}\text { ipacto } \\
\text { ses ma }\end{array}$ & $\begin{array}{l}\text { ublica } \\
\text { tacado }\end{array}$ & em áreas & $\begin{array}{l}\text { e subárea } \\
\text { quinqüêni }\end{array}$ & medi & & & & \\
\hline \multirow[t]{2}{*}{ No } & \multirow{2}{*}{$\begin{array}{l}\text { Medicina: } \\
\text { Áreas e Subáreas }\end{array}$} & \multicolumn{9}{|c|}{ Impacto das Publicações } \\
\hline & & Brasil & Mundo & Holanda & Finlândia & EUA & Canadá & Dinamarca & Suécia & $\begin{array}{c}\text { Média } \\
\text { seis Países }\end{array}$ \\
\hline 1 & $\begin{array}{l}\text { Anestesiologia e cuidados } \\
\text { intensivos }\end{array}$ & 3,7 & 3,2 & 3,6 & 4,0 & 3,8 & 3,7 & 4,2 & 3,9 & 3,9 \\
\hline 2 & Cardiologia e hematologia & 5,3 & 7,3 & 9,2 & 9,3 & 8,7 & 8,5 & 8,5 & 8,7 & 8,8 \\
\hline 3 & $\begin{array}{l}\text { Cardiologia e sistema } \\
\text { respiratório }\end{array}$ & 4,2 & 5,0 & 7,2 & 6,9 & 6,5 & 6,5 & 6,1 & 6,5 & 6,6 \\
\hline 4 & Cirurgia & 1,1 & 2,5 & 3,5 & 3,6 & 3,5 & 2,7 & 3,7 & 3,0 & 3,3 \\
\hline 5 & Dermatologia & 1,1 & 2,9 & 4,7 & 4,6 & 3,7 & 5,0 & 3,9 & 3,3 & 4,2 \\
\hline 6 & $\begin{array}{l}\text { Endocrinologia, metabolismo } \\
\text { e nutrição }\end{array}$ & 5,9 & 7,4 & 7,5 & 9,9 & 8,7 & 8,7 & 8,3 & 9,0 & 8,7 \\
\hline 7 & Farmacotoxicologia & 2,3 & 4,0 & 4,5 & 5,7 & 4,0 & 4,6 & 4,9 & 5,1 & 4,8 \\
\hline 8 & $\begin{array}{l}\text { Gastroenterologia } \\
\text { e hepatologia }\end{array}$ & 2,7 & 5,4 & 8,1 & 7,0 & 7,4 & 7,3 & 7,0 & 7,2 & 7,3 \\
\hline 9 & Hematologia & 4,2 & 6,7 & 8,9 & 7,3 & 9,2 & 8,5 & 8,2 & 7,6 & 8,3 \\
\hline 10 & $\begin{array}{l}\text { Imunologia clínica } \\
\text { e doenças infecciosas }\end{array}$ & 5,1 & 5,3 & 7,3 & 6,3 & 6,6 & 6,6 & 5,4 & 5,5 & 6,3 \\
\hline 11 & $\begin{array}{l}\text { Medicina ambiental } \\
\text { e saúde pública }\end{array}$ & 3,0 & 3,7 & 4,8 & 4,5 & 4,6 & 4,3 & 4,4 & 4,0 & 4,4 \\
\hline 12 & Medicina da reprodução & 1,9 & 3,3 & 3,7 & 3,4 & 3,9 & 4,1 & 3,6 & 3,7 & 3,7 \\
\hline 13 & $\begin{array}{l}\text { Medicina, diagnóstico } \\
\text { e tratamento }\end{array}$ & 2,6 & 4,4 & 5,8 & 6,0 & 5,5 & 5,2 & 5,3 & 5,2 & 5,5 \\
\hline 14 & Medicina interna geral & 17,6 & 5,9 & 15,2 & 15,7 & 10,6 & 12,2 & 13,2 & 12,6 & 13,3 \\
\hline 15 & $\begin{array}{l}\text { Medicina laboratorial } \\
\text { e tecnologia médica }\end{array}$ & 4,0 & 6,1 & 7,6 & 10,3 & 7,8 & 7,7 & 6,5 & 6,9 & 7,8 \\
\hline 16 & Medicina, órgãos e sistemas & 2,7 & 4,9 & 6,4 & 4,6 & 5,5 & 6,1 & 5,4 & 5,3 & 5,6 \\
\hline 17 & Medicina, tópicos gerais & 2,6 & 8,1 & 12,1 & 10,8 & 12,2 & 11,8 & 9,0 & 8,5 & 10,7 \\
\hline 18 & Neurologia & 4,8 & 4,9 & 6,4 & 7,0 & 6,6 & 6,9 & 6,3 & 6,5 & 6,6 \\
\hline 19 & Odontologia e cirurgia bucal & 1,2 & 2,2 & 2,8 & 2,8 & 2,5 & 2,3 & 3,3 & 3,8 & 2,9 \\
\hline 20 & Oftalmologia & 1,5 & 2,6 & 3,7 & 3,0 & 3,4 & 3,0 & 3,0 & 3,7 & 3,3 \\
\hline 21 & Oncogênese e câncer & 3,5 & 7,7 & 7,8 & 9,3 & 10,2 & 9,9 & 8,5 & 7,6 & 8,9 \\
\hline 22 & Oncologia & 3,1 & 7,3 & 7,5 & 9,8 & 9,9 & 10,2 & 8,2 & 8,1 & 9,0 \\
\hline 23 & Ortopedia e medicina esportiva & 0,9 & 1,4 & 1,6 & 2,2 & 1,6 & 2,1 & 2,3 & 2,1 & 2,0 \\
\hline 24 & Otorrinolaringologia & 1,2 & 1,8 & 2,7 & 1,2 & 2,4 & 1,8 & 1,6 & 2,3 & 2,0 \\
\hline 25 & Pediatria & 1,9 & 2,5 & 3,3 & 4,2 & 3,3 & 3,3 & 4,8 & 4,0 & 3,8 \\
\hline 26 & Psicologia clínica e psiquiatria & 3,3 & 5,2 & 4,7 & 5,4 & 6,5 & 5,1 & 5,6 & 4,8 & 5,4 \\
\hline 27 & $\begin{array}{l}\text { Radiologia, medicina } \\
\text { nuclear e por imagem }\end{array}$ & 1,6 & 3,7 & 5,2 & 3,4 & 4,6 & 4,0 & 4,5 & 3,6 & 4,2 \\
\hline 28 & Reumatologia & 2,8 & 4,6 & 6,8 & 4,9 & 6,0 & 5,4 & 5,3 & 4,7 & 5,5 \\
\hline 29 & Saúde pública & 0,7 & 2,3 & 2,6 & 2,3 & 2,6 & 2,2 & 1,8 & 2,0 & 2,3 \\
\hline 30 & Serviços em saúde & 0,4 & 2,4 & 2,8 & 1,8 & 2,8 & 2,9 & 2,6 & 2,4 & 2,6 \\
\hline & Urologia & 3,7 & 4,0 & 5,5 & 5,0 & 5,4 & 6,1 & 5,4 & 5,5 & 5,5 \\
\hline Mé & dia dos Países & 3,1 & 4,5 & 5,9 & 5,9 & 5,8 & 5,8 & 5,5 & 5,4 & 5,7 \\
\hline
\end{tabular}

Fonte: Science Indicators 2001. Base de acesso Deluxe. Institute for Scientific Information (ISI), EUA. 
mesmas subáreas é, igualmente, a de melhor desempenho também no Brasil. A tabela 6 mostra que no cômputo geral o Brasil, com 52,8\% de artigos médicos citados, está situado cerca de 9 e 15 pontos percentuais abaixo da média mundial $(61,6 \%)$ e da média dos seis países de melhor desempenho (67,9\%). Não obstante, em várias subáreas (endocrinologia, farmacotoxicologia, hematologia, imunologia clínica, medicina ambiental, medicina interna, medicina laboratorial, otorrinolaringologia, reumatologia e urologia), esse distanciamento é bem menor, tanto em relação ao mundo como em relação aos seis países da tabela 6 . Como já comentado, observa-se que as subáreas defasadas em relação à média nacional da grande área, são praticamente as mesmas também defasadas quanto ao desempenho médio mundial ou quanto ao dos seis países mais destacados no ranking do indicador. Mas, nesse grupo que também apresenta índices geralmente baixos em relação às três médias (a exceção é a otorrinolaringologia), o distanciamento do Brasil é usualmente maior seja em relação ao mundo ou aos países da tabela 6 .

A tabela 7 destaca o outro indicador qualitativo, o impacto das publicações, comparando o Brasil com os índices mundiais e com os seis países de melhor desempenho acima relacionados. No âmbito dos seis países, a medicina interna é a mais destacada em impacto $(13,3)$, seguida de tópicos gerais em medicina, oncologia, oncogênese e câncer, cardiologia e hematologia, endocrinologia, hematologia, medicina laboratorial, gastroenterologia e hepatologia e cardiologia e sistema respiratório. O Brasil, com impacto de 3,1 (como comentado, este é o índice base de acesso Deluxe), se situa bem abaixo da média mundial $(4,5)$ e especialmente da média dos seis países mais destacados $(5,7)$. Novamente, a maior contribuição para este índice mais baixo do impacto brasileiro provém das subáreas de serviços em saúde, saúde pública, ortopedia e medicina esportiva, dermatologia, cirurgia, otorrinolaringologia, odontologia e cirurgia bucal, oftalmologia, radiologia, pediatria e medicina da reprodução, que são predominantemente as mesmas com menor desempenho também nas médias dos seis países. As mesmas considerações feitas com relação ao percentual de artigos citados parecem ser também válidas na análise dessas subáreas. Quanto ao grupo de áreas com melhor desempenho no Brasil, além do destaque, já mencionado, da pesquisa em medicina interna, com o mais ele- vado índice de impacto $(17,6)$ no ranking mundial, outras subáreas também apresentam índices superiores à média nacional e mais próximas à média dos seis países: endocrinologia, cardiologia e hematologia, imunologia clínica, neurologia, cardiologia e sistema respiratório, hematologia, medicina laboratorial, anestesiologia e urologia. Observa-se aqui, todavia, na comparação com o índice de percentual de artigos citados, igual distanciamento entre o Brasil e os seis países e menor coincidência na lista do Brasil com a dos países selecionados. Um dado a ser destacado é o apresentado pela anestesiologia, cujo índice de impacto $(3,7)$ se situa acima da média mundial da área $(3,2)$ e muito próximo à média dos seis países mais qualificados $(3,9)$.

Uma análise aprofundada sobre a defasagem das subáreas com menor desempenho nos indicadores qualitativos em relação ao conjunto da área médica poderia indicar que, na maioria dos casos, se trata de campos de pesquisa mais recentes no Brasil, desprovidos de massa crítica de pesquisadores e, portanto, ainda carentes da capacitação em recursos humanos qualificados para assegurar o melhor desempenho da subárea. De fato, em várias delas verifica-se escassez de programas de pós-graduação, por exemplo (ver Tabela 13 adiante). Todavia há, aparentemente, outros fatores envolvidos, pois, na comparação mundial, estas mesmas subáreas também apresentam tal defasagem de desempenho tanto no ranking mundial como, surpreendentemente, nos indicadores dos seis países mais qualificados nestes parâmetros ( Tabelas 6 e 7). Já no que diz respeito à área de saúde pública, com expressiva produção científica (5 posição no ranking da tabela 5), trazida pelo autor neste trabalho para fazer parte dos dados da pesquisa em medicina devido à sua reconhecida inserção, no Brasil, na pesquisa em saúde coletiva, pode-se especular que seu baixo desempenho nos indicadores qualitativos provém da publicação compartilhada de artigos em revistas das ciências sociais, uma área em que ocorre, sabidamente, menores índices de citações entre pares. Isto se confirma pela observação de que em outra subárea, com posição destacada nesses indicadores (medicina ambiental e saúde pública), o componente saúde pública tem peso substancial no desempenho apresentado nos índices qualitativos da subárea. Carece de explicação, todavia, a origem de outros fatores condicionantes que justifiquem um mais baixo índice de desempenho 
qualitativo observado em certas áreas tanto no Brasil como no mundo e mesmo nos países mais avançados na pesquisa médica.

\section{Pesquisa biomédica no Brasil}

O conjunto de subáreas que compõe a área biomédica, extraído das bases de dados do ISI, compreende um total de 11 subáreas: bioquímica e biofísica, biologia celular e do desenvolvimento, biologia experimental, biologia molecular e genética, biotecnologia e microbiologia aplicada, endocrinologia, metabolismo e nutrição, farmacologia, imunologia, microbiologia e neurociências. No qüinqüênio 1997-2001 a produção científica mundial da grande área foi de cerca de um quinto da produção qualificada do somatório de todas as áreas. A tabela 8 apresenta os indicadores quali-quantitativos dos 30 países cientificamente mais produtivos nesta área no qüinqüênio em análise. Novamente verifica-se que os primeiros sete países do ranking mundial de todas as áreas (Tabela 1, ranking de 2001) ocupam as mesmas posições relativas também no ranking da produção na área biomédica. Também estão à frente da posição brasileira na área biomédica todos os 17 países da tabela 2. Similarmente ao verificado com a área médica, aqui também vários países europeus (Holanda, Suécia, Suíça, Escócia, Bélgica e Dinamarca) ocupam posição mais destacada na produção em ciências biomédicas em comparação com o ranking mundial (ano 2001) mostrado na tabela 1. Igualmente, como na área médica, alguns países (Rússia, China, Índia, Coréia do Sul, Taiwan e Brasil) cederam suas posições para o grupo europeu que avançou no ranking da área biomédica. Três outros ocupantes da tabela 1 não estão presentes no ranking da produção na área biomédica (Grécia, Turquia e República Tcheca), entrando em seus lugares Argentina, Hungria e Nova Zelândia. Já em relação à medicina, o ranking das ciências biomédicas inclui, além da Argentina e Hungria, também a Polônia e o México, que ocupam as posições da Grécia, África do Sul e País de Gales. Estranhamente, sai também a Turquia, apesar de sua destacada presença (20a posição) no ranking da área médica.

Como mostrado na tabela 8 , no período 1997-2001, um total de 711.734 artigos completos foram publicados nas revistas da área biomédica pelo conjunto de países que compõe a base de dados Deluxe do ISI, representando $19,6 \%$ do total mundial de 3.630 .750 artigos de todas as 105 áreas e subáreas que compõem essa base de dados. A produção desses 30 países representa $94,9 \%$ do total mundial da área. Vale ressaltar que o somatório das contribuições de cada país na tabela alcança um total de 835.921 artigos, compondo com os dados dos outros 145 países do ranking mundial um total geral de 880.720 artigos da área biomédica. Com esse total geral, a dupla contagem da base de dados é de $23,4 \%$, superior aos $16,0 \%$ observados no ranking da medicina (Tabela 4). A origem da dupla contagem já foi apontada mais acima.

Novamente observa-se que, excluída a destacada participação dos EUA $(33,1 \%)$, a contribuição de cada país para o volume total de artigos da área biomédica variou dentro dos limites de 0,4\% (Nova Zelândia, México e Hungria) a 8,7\% (Japão, o segundo país do ranking). Quanto à participação interna na produção científica total em cada país, a distribuição foi também mais homogênea. As exceções ficaram por conta da Rússia (6,9\%), China (8,0\%), Índia (11,8\%), Polônia $(12,7 \%)$ e Taiwan $(12,8 \%)$. Para todos os demais países a produção de artigos na área biomédica variou de $15 \%$ a $23 \%$ da sua produção total interna. Como se verifica, em nenhum país a proporção da produção interna de artigos atingiu na área biomédica, índices tão altos como verificado com vários países, especialmente os europeus, além da Turquia, na área médica. Com referência ao Brasil, a área biomédica apresentou uma produção ligeiramente superior à área médica. Foram 8.366 artigos no período (0,9\% da área no mundo). Com essa produção, o Brasil ocupa a 21a posição no ranking mundial da área e a segunda na produção interna, representando $19,0 \%$ do total de artigos indexados do país na base Deluxe do ISI (Tabelas 3 e 8 ).

A tabela 8 apresenta também o desempenho dos países na área biomédica quanto aos indicadores percentual de artigos citados e impacto das publicações. Nota-se, novamente, várias mudanças nas posições relativas dos países no ranking qualitativo (números entre parêntesis nas colunas da tabela), com expressivo destaque de alguns países europeus no que concerne a esses indicadores. Assim, quanto ao percentual de artigos citados, o índice médio dos 30 países da tabela para o indicador no período foi de $75,1 \%$ e de $73,9 \%$ para a área no mundo, índices muito superiores ao índice médio mundial para todas as áreas $(58,0 \%)$ e bem mais elevado também do que os mesmos índi- 
Tabela 8

Área biomédica: produção científica 1997-2001. Desempenho quali-quantitativo dos 30 países mais produtivos da área no ranking mundial no período.

\begin{tabular}{|c|c|c|c|c|c|c|c|}
\hline \multirow{2}{*}{$\begin{array}{l}\text { Ranking 1997-2001 } \\
\text { Países }\end{array}$} & \multicolumn{3}{|c|}{ Produção Científica } & \multirow{2}{*}{$\begin{array}{l}\text { Artigos } \\
\text { Citados } \\
\text { Número }^{\star}\end{array}$} & \multirow{2}{*}{$\begin{array}{c}\text { Artigos } \\
\text { Citados } \\
\%^{\star}\end{array}$} & \multirow{2}{*}{$\begin{array}{l}\text { Total de } \\
\text { Citações } \\
\text { Número* }^{*}\end{array}$} & \multirow{2}{*}{$\begin{array}{c}\text { Impacto } \\
\text { da Ârea } \\
\text { Índice* }\end{array}$} \\
\hline & Artigos & \% no País & $\begin{array}{l}\text { \% Área } \\
\text { no País }\end{array}$ & & & & \\
\hline 1. EUA & 291.291 & 33,1 & 23,0 & 229.736 & $78,9(2)$ & 3.213 .388 & $11,0(2)$ \\
\hline 2. Japão & 76.686 & 8,7 & 22,8 & 54.395 & $70,9(19)$ & 470.280 & $6,1(19)$ \\
\hline 3. Alemanha & 62.633 & 7,1 & 19,7 & 47.821 & $76,4(7)$ & 536.845 & $8,6(5)$ \\
\hline 4. Inglaterra & 61.481 & 7,0 & 21,1 & 47.612 & $77,4(3)$ & 589.454 & $9,6(3)$ \\
\hline 5. França & 49.211 & 5,6 & 21,3 & 36.634 & $74,4(13)$ & 385.581 & $7,8(10)$ \\
\hline 6. Canadá & 36.488 & 4,1 & 22,0 & 27.696 & $75,9(8)$ & 311.969 & $8,6(6)$ \\
\hline 7. Itália & 31.765 & 3,6 & 21,6 & 22.821 & $71,8(18)$ & 205.850 & $6,5(17)$ \\
\hline 8. Holanda & 21.038 & 2,4 & 22,7 & 16.289 & $77,4(4)$ & 172.503 & $8,2(7)$ \\
\hline 9. Espanha & 20.288 & 2,3 & 19,6 & 14.227 & $70,1(20)$ & 112.151 & $5,5(20)$ \\
\hline 10. Austrália & 19.839 & 2,3 & 19,2 & 15.010 & $75,7(9)$ & 142.640 & $7,2(15)$ \\
\hline 11. Suécia & 19.258 & 2,2 & 26,4 & 14.781 & $76,8(6)$ & 150.217 & $7,8(11)$ \\
\hline 12. Suíça & 16.303 & 1,9 & 24,4 & 12.979 & $79,6(1)$ & 189.662 & $11,6(1)$ \\
\hline 13. Escócia & 11.096 & 1,3 & 24,2 & 8.542 & $77,0(5)$ & 99.211 & $8,9(4)$ \\
\hline 14. Bélgica & 10.663 & 1,2 & 22,2 & 8.041 & $75,4(11)$ & 81.516 & $7,6(12)$ \\
\hline 15. Dinamarca & 9.606 & 1,1 & 25,8 & 7.251 & $75,5(10)$ & 69.683 & $7,3(14)$ \\
\hline 16. China & 9.221 & 1,0 & 8,0 & 5.315 & $57,6(28)$ & 30.273 & $3,3(28)$ \\
\hline 17. Índia & 9.074 & 1,0 & 11,8 & 5.039 & $55,5(30)$ & 21.184 & $2,3(30)$ \\
\hline 18. Coréia do Sul & 8.792 & 1,0 & 15,9 & 5.399 & $61,4(25)$ & 30.930 & $3,5(25)$ \\
\hline 19. Israel & 8.772 & 1,0 & 19,1 & 6.510 & $74,2(15)$ & 71.821 & $8,2(8)$ \\
\hline 20. Rússia & 8.528 & 0,9 & 6,9 & 4.665 & $54,7(30)$ & 29.981 & $3,5(26)$ \\
\hline 21. Brasil & 8.366 & 0,9 & 19,0 & 5.054 & $60,4(26)$ & 27.161 & $3,3(29)$ \\
\hline 22. Finlândia & 8.108 & 0,9 & 23,4 & 6.087 & $75,1(12)$ & 61.811 & $7,6(13)$ \\
\hline 23. Áustria & 6.750 & 0,8 & 20,1 & 5.012 & $74,3(14)$ & 53.885 & $8,0(9)$ \\
\hline 24. Taiwan & 5.808 & 0,7 & 12,8 & 3.767 & $64,9(22)$ & 21.795 & $3,8(24)$ \\
\hline 25. Polônia & 5.457 & 0,6 & 12,7 & 3.458 & $63,4(24)$ & 26.672 & $4,9(21)$ \\
\hline 26. Noruega & 4.342 & 0,5 & 18,2 & 3.222 & $74,2(16)$ & 28.805 & $6,6(16)$ \\
\hline 27. Argentina & 4.123 & 0,5 & 21,0 & 2.604 & $60,0(27)$ & 14.018 & $3,4(27)$ \\
\hline 28 Hungria & 3.775 & 0,4 & 20,5 & 2.558 & $67,8(21)$ & 18.276 & $4,8(22)$ \\
\hline 29. México & 3.704 & 0,4 & 16,9 & 2.380 & $64,3(23)$ & 15.090 & $4,1(23)$ \\
\hline 30. Nova Zelândia & 3.455 & 0,4 & 16,2 & 2.537 & 73,4 (17) & 22.019 & $6,4(18)$ \\
\hline Dados da tabela & 835.921 & 94,9 & 19,3 & 627.442 & 75,1 & 7.204 .671 & 8,6 \\
\hline Outros 145 países & 44.799 & 5,1 & - & - & - & - & - \\
\hline Total Mundo (A) & 880.720 & 100,0 & - & - & - & - & - \\
\hline Total Base Deluxe (B) & 711.734 & - & 19,6 & 525.711 & 73,9 & 5.698 .921 & 8,0 \\
\hline Sobreposição A / B, \% & 23,4 & - & - & - & - & - & - \\
\hline Total Artigos Mundo & 3.630 .750 & - & - & 2.104 .746 & 58,0 & 14.704 .538 & 4,1 \\
\hline
\end{tabular}

* Números entre parêntesis indicam posição dos 30 países no ranking do respectivo indicador.

Fonte: Science Indicators, 2001. Dados da Base Deluxe. Institute for Scientific Information (ISI), EUA.

ces na área médica que foram de $63,4 \%$ para os 30 países e de $61,6 \%$ para os dados mundiais da área (Tabela 4). Entre os participantes da tabela 8, é possível destacar países qualitativamente mais diferenciados, como Suíça $(79,6 \%)$, Holanda $(77,4 \%)$, Escócia $(77,0 \%)$, Suécia $(76,8 \%)$, Austrália $(75,7 \%)$ e Dinamarca $(75,5 \%)$, que ao lado de países bem situados no ranking quantitativo como EUA $(78,9 \%)$, Inglaterra $(77,4 \%)$, Alemanha $(76,4 \%)$ e Canadá $(75,9 \%)$ compõem o grupo mais destacado no indicador. Tão elevados índices de artigos citados, independentemente do número de publicações de cada país na área, comprovam a aceitação mundial da pesquisa biomédica praticada nesses países líderes. Constata-se tam- 
bém, a partir dos dados da tabela, o deslocamento de posições ocupadas por alguns países entre os primeiros colocados no ranking da produção (Japão, França, Itália e Espanha), que passam a ocupar posições inferiores no ranking do percentual de artigos citados. A confirmação de bom desempenho bem como a defasagem (menor porcentagem de citações relativamente ao total de publicações) dos países pode ser visualizada também na tabela 8 na coluna índice de impacto (razão entre o total de citações e o número de publicações). Os índices médios dos 30 países da tabela $(8,6)$ e a média mundial da área biomédica $(8,0)$ são muito superiores aos índices da medicina (5,1 para os 30 países e 4,5 para a média mundial da área médica) e mais ainda em relação à média mundial para todas as áreas $(4,1)$. Constata-se, na pesquisa biomédica, o excelente desempenho da Suíça $(11,6)$, EUA $(11,0)$, Inglaterra $(9,6)$, Escócia $(8,9)$, Alemanha e Canadá $(8,6)$, Holanda e Israel $(8,2)$ e Áustria $(8,0)$.

Quanto ao Brasil, no qüinqüênio 19972001 foram publicados 8.366 artigos pelo conjunto das subáreas que compõem a área biomédica, colocando o País na 21a posição no ranking mundial da área. Já em relação aos artigos citados $(60,4 \%)$ e índice de impacto $(3,3)$ nosso desempenho está muito abaixo dos parâ- metros mundiais da área $(73,9 \%$ e 8,0 , respectivamente), o que alterou o posicionamento do Brasil, situando-o nas 26a e 29a posições nos dois rankings qualitativos respectivamente. Não obstante, tais índices são bem superiores aos índices médios brasileiros para todas as áreas (50,4\% de artigos citados e 1,8 de impacto) e também em relação à própria área médica (52,8\% e 2,8 , respectivamente). Constata-se ainda que entre as áreas mais destacadas no Brasil nestes indicadores encontram-se diversas subáreas da área biomédica: imunologia $(68,9 \%$ e 4,3$)$; bioquímica e biofísica $(67,2 \%$ e $3,8)$, neurociências $(65,1 \%$ e 4,1$)$; microbiologia $(60,1 \%$ e 3,2$)$ e biologia celular e do desenvolvimento $(60,0 \%$ e 3,0$)$.

A tabela 9 apresenta o desempenho qualiquantitativo da pesquisa na área biomédica no Brasil. As onze áreas e subáreas estão listadas em função da produção de artigos indexados no ISI no período 1997-2001. A contribuição brasileira na produção científica mundial na área biomédica foi de 1,3\% no período 1997 2001, um pouco acima da média nacional na produção mundial total neste mesmo qüinqüênio $(1,2 \%)$. Três subáreas, no entanto, superam ainda mais este limite: biotecnologia e microbiologia aplicada $(2,5 \%)$, microbiologia $(1,7 \%)$ e biologia molecular e genética $(1,6 \%)$. Pode-

\section{Tabela 9}

Produção científica do Brasil na área biomédica. Indicadores quali-quantitativos no qüinqüênio 1997-2001.

\begin{tabular}{|c|c|c|c|c|c|c|c|}
\hline \multirow[t]{2}{*}{ No } & \multirow[t]{2}{*}{ Medicina: Áreas e Subáreas } & \multicolumn{2}{|c|}{ Artigos } & \multicolumn{2}{|c|}{ Artigos Citados } & \multicolumn{2}{|c|}{ Citações } \\
\hline & & Total & $\begin{array}{c}\% \text { Brasil } \\
\text { no Mundo* }\end{array}$ & Total & $\%$ & Total & $\begin{array}{l}\text { Indice de } \\
\text { Impacto }\end{array}$ \\
\hline 1 & Microbiologa & 1.380 & 1,7 & 829 & 60,1 & 4.442 & 3,2 \\
\hline 2 & Bioquímica e biofísica & 1.229 & 0,9 & 826 & 67,2 & 4.646 & 3,8 \\
\hline 3 & Neurociências & 1.159 & 0,8 & 755 & 65,1 & 4.700 & 4,1 \\
\hline 4 & Farmacologia & 1.133 & 1,5 & 648 & 57,2 & 2.567 & 2,3 \\
\hline 5 & Biologia molecular e genética & 989 & 1,6 & 521 & 52,7 & 3.041 & 3,1 \\
\hline 6 & Imunologia & 714 & 1,1 & 492 & 68,9 & 3.046 & 4,3 \\
\hline 7 & Biotecnologia e microbiologia aplicada & 556 & 2,5 & 275 & 49,5 & 831 & 1,5 \\
\hline 8 & Endocrinologia, metabolismo e nutrição & 459 & 1,0 & 273 & 59,5 & 1.852 & 4,0 \\
\hline 9 & Biologia celular e do desenvolvimento & 335 & 0,7 & 201 & 60,0 & 1.017 & 3,0 \\
\hline 10 & Fisiologia & 235 & 1,1 & 131 & 55,8 & 412 & 1,8 \\
\hline 11 & Biologia experimental & 177 & 0,9 & 103 & 58,2 & 607 & 3,4 \\
\hline \multicolumn{2}{|r|}{ Totais das Áreas/Subáreas: Brasil } & 8.366 & 1,3 & 5.054 & 60,4 & 27.161 & 3,3 \\
\hline \multicolumn{2}{|r|}{ Total Mundial das Áreas/Subáreas } & 711.734 & $19,6^{\star *}$ & 525.711 & 73,9 & 5.698 .921 & 8,0 \\
\hline \multicolumn{2}{|c|}{ Total Mundial todas as Áreas } & 3.630 .750 & 100,0 & 2.104 .746 & 58,0 & 14.704 .538 & 4,1 \\
\hline
\end{tabular}

* Refere-se à contribuição do Brasil na produção total da respectiva área.

** Refere-se ao percentual de publicações da área sobre a produção mundial em todas as áreas.

Fonte: Science Indicators 2001. Base de acesso Deluxe. Institute for Scientific Information (ISI), EUA. 
se observar, mais uma vez, a regra da não equivalência entre contribuição quantitativa e desempenho qualitativo. Quanto a estes indicadores, como acima mencionado, as médias da área biomédica são bem superiores às médias brasileiras de todas as áreas. No percentual de artigos citados, os índices variaram de 49,5\% a $68,9 \%$, mas nenhuma subárea superou a elevada média mundial da área biomédica $(73,9 \%)$. Apenas uma subárea, biotecnologia e microbiologia aplicada, apresentou o indicador abaixo da média nacional de todas as áreas. No que diz respeito ao impacto das publicações, como acima mencionado, o Brasil ainda apresenta índices muito baixos nesta área, apesar da considerável melhoria ocorrida nos últimos 20 anos.

O desempenho do Brasil nos dois indicadores qualitativos em comparação aos índices mundiais e aos dos seis países mais destacados nesses mesmos indicadores no qüinqüênio 1997-2001 é mostrado nas tabelas 10 e 11. A tabela 10 compara o percentual de artigos citados nas 11 subáreas biomédicas (listadas em ordem alfabética) pelo Brasil, com a média mundial e com os seis países de melhor desempenho no indicador: Suíça, EUA, Inglaterra, Escócia, Holanda e Alemanha. A comparação com os países de mais elevado desempenho possibilita melhor situar o desafio a ser vencido pela pesquisa brasileira na área biomédica para colocá-la no patamar dos índices de citação que melhor qualifica a pesquisa feita na área. Apesar de bem superiores às médias brasileiras de todas as áreas e do bom desempenho em certas subáreas, os índices brasileiros (média de 60,4\% de citações) são ainda muito inferiores à média mundial da área biomédica $(73,9 \%)$ e menos ainda na comparação com os países mais destacados (média geral de 76,3\% de artigos citados), representando distanciamentos de cerca de 13 e 16 pontos percentuais para baixo na comparação com as duas médias, respectivamente. Claramente, as médias mundiais são fortemente influenciadas pelos 30 países da tabela 8 , onde se insere o Brasil, mas também pelos seis países da tabela 10 com suas elevadas médias de citações em cada subárea. O distanciamento das subáreas brasileiras em relação aos índices mundiais é mais crítico em biologia molecular e genética, biologia celular e do desenvolvimento (duas das três subáreas de melhor desempenho qualitativo mundial) e mais a biologia experimental e a microbiologia. Já as subáreas de imunologia, farmacologia, neurociências e bioquímica e biofísica se situam bem mais próximas das médias mundiais de cada subárea.

Quanto ao impacto das publicações, a tabela 11 apresenta os dados do Brasil para comparação com os índices mundiais e com os seis países de melhor desempenho neste indicador. Entre as 11 subáreas da tabela, a biologia celular e do desenvolvimento, uma área de pesquisa na qual se situa a maior parte dos avanços da biomedicina moderna, apresenta o maior índice de impacto das publicações (média de 15,9 no mundo e 17,4 entre os seis países). Em seguida, tanto no mundo como nos países destacados, aparecem biologia molecular e genética (10,6 e 13,3), imunologia $(9,7$ e 11,0) e bioquímica e biofísica $(9,1$ e 11,0), respectivamente. Como acima mencionado, o Brasil com impacto de 3,3 apesar da considerável melhoria ocorrida nos últimos 20 anos se situa ainda bem abaixo da média mundial $(8,0)$ e especialmente dos seis países mais destacados $(9,2)$.

A maior contribuição para este baixo índice do impacto das publicações brasileiras provém das subáreas de biotecnologia e microbiologia aplicada (índice 1,5$)$, fisiologia $(1,8)$ e farmacologia $(2,3)$. Como mencionado na parte da metodologia, a contribuição negativa da fisiologia e mesmo da farmacologia neste indicador pode estar influenciada pela não inclusão dos artigos (e conseqüentemente das citações) de pesquisadores dessas duas áreas cujos artigos foram publicados no Brazilian Journal of Medical and Biological Research, classificado pelo ISI exclusivamente na área médica. Ressalte-se que todas as outras oito subáreas apresentam índices superiores à média geral brasileira. Todavia, mesmo nas áreas com melhores índices de impacto: imunologia $(4,3)$, neurociências $(4,1)$, endocrinologia, metabolismo e nutrição $(4,0)$ e bioquímica e biofísica $(3,8)$, o desempenho está ainda muito aquém daquele apresentado nestas mesmas áreas pelos países mais destacados, ou mesmo pelo conjunto dos países como um todo (Tabela 11).

Numa comparação com a área médica, verifica-se que em razão do seu extraordinário desempenho mundial, a área biomédica no Brasil está em situação mais crítica no desempenho qualitativo do que a área médica, em que várias subáreas e campos de pesquisa apresentam menor distanciamento com as respectivas subáreas do conjunto dos países. 


(

\section{Tabela 10}

Indicadores qualitativos: \% artigos citados na área biomédica.

Comparação Brasil, mundo e seis países mais destacados na área no qüinqüênio 1997-2001.

\begin{tabular}{|c|c|c|c|c|c|c|c|c|c|c|}
\hline \multirow[t]{2}{*}{ No } & \multirow{2}{*}{$\begin{array}{l}\text { Medicina: } \\
\text { Áreas e Subáreas }\end{array}$} & \multicolumn{9}{|c|}{ \% de Artigos Citados na Área Biomédica } \\
\hline & & Brasil & Mundo & Suíça & EUA & Inglaterra & Escócia & Holanda & Alemanha & $\begin{array}{c}\text { Média } \\
\text { seis Países }\end{array}$ \\
\hline 1 & Bioquímica e biofísica & 67,2 & 77,8 & 83,1 & 82,5 & 80,5 & 79,7 & 82,1 & 81,0 & 81,5 \\
\hline 2 & $\begin{array}{l}\text { Biologia celular e do } \\
\text { desenvolvimento }\end{array}$ & 60,0 & 78,5 & 84,0 & 82,3 & 82,1 & 81,8 & 82,8 & 81,1 & 82,4 \\
\hline 3 & Biologia experimental & 58,2 & 71,9 & 78,9 & 76,0 & 77,0 & 78,6 & 70,2 & 71,9 & 75,4 \\
\hline 4 & Biologia molecular e genética & 52,7 & 77,2 & 84,3 & 81,9 & 83,0 & 81,1 & 83,6 & 79,8 & 82,3 \\
\hline 5 & $\begin{array}{l}\text { Biotecnologia e } \\
\text { microbiologia aplicada }\end{array}$ & 49,5 & 60,9 & 74,1 & 69,5 & 67,0 & 67,2 & 69,5 & 69,9 & 69,5 \\
\hline 6 & $\begin{array}{l}\text { Endocrinologia, } \\
\text { metabolismo e nutrição }\end{array}$ & 59,5 & 70,6 & 73,1 & 74,6 & 74,6 & 74,6 & 73,9 & 70,5 & 73,6 \\
\hline 7 & Farmacologia & 57,2 & 66,1 & 72,8 & 71,7 & 72,1 & 74,0 & 71,7 & 67,3 & 71,6 \\
\hline 8 & Fisiologia & 55,8 & 65,9 & 70,6 & 68,1 & 71,6 & 72,7 & 64,6 & 73,0 & 70,1 \\
\hline 9 & Imunologia & 68,9 & 77,2 & 82,4 & 80,7 & 77,6 & 79,2 & 80,1 & 78,2 & 79,7 \\
\hline 10 & Microbiologa & 60,1 & 73,4 & 79,7 & 79,3 & 77,2 & 74,7 & 78,8 & 76,0 & 77,6 \\
\hline & Neurociências & 65,1 & 74,7 & 76,7 & 78,4 & 76,6 & 74,8 & 74,8 & 75,3 & 76,1 \\
\hline \multicolumn{2}{|c|}{ Médias } & 60,4 & 73,9 & 78,2 & 76,8 & 76,3 & 76,2 & 75,6 & 74,9 & 76,3 \\
\hline
\end{tabular}

Fonte: Science Indicators 2001. Base de acesso Deluxe. Institute for Scientific Information (ISI), EUA.

\begin{tabular}{|c|c|c|c|c|c|c|c|c|c|c|}
\hline & $\begin{array}{l}\text { ela } 11 \\
\text { icadores qualitativos: índice de } \\
\text { nparação Brasil, mundo e seis }\end{array}$ & $\begin{array}{l}\text { pacto d } \\
\text { es mais }\end{array}$ & $\begin{array}{l}\text { publicaçõ } \\
\text { estacados }\end{array}$ & na áre: & nédic: & $1997-2001$ & & & & \\
\hline \multirow[t]{2}{*}{ No } & \multirow{2}{*}{$\begin{array}{l}\text { Medicina: } \\
\text { Áreas e Subáreas }\end{array}$} & \multicolumn{9}{|c|}{ Impacto das Publicações } \\
\hline & & Brasil & Mundo & Suíça & EUA & Inglaterra & Escócia & Holanda & Alemanha & $\begin{array}{c}\text { Média } \\
\text { seis Países }\end{array}$ \\
\hline 1 & Bioquímica e biofísica & 3,8 & 9,1 & 13,0 & 12,1 & 11,0 & 10,6 & 9,8 & 9,6 & 11,0 \\
\hline 2 & $\begin{array}{l}\text { Biologia celular e do } \\
\text { desenvolvimento }\end{array}$ & 3,0 & 15,9 & 18,7 & 21,8 & 18,3 & 15,4 & 15,4 & 14,8 & 17,4 \\
\hline 3 & Biologia experimental & 3,4 & 6,8 & 10,3 & 8,3 & 8,1 & 9,6 & 6,3 & 7,5 & 8,4 \\
\hline 4 & Biologia molecular e genética & 3,1 & 10,6 & 15,6 & 13,6 & 13,9 & 12,5 & 12,2 & 11,9 & 13,3 \\
\hline 5 & $\begin{array}{l}\text { Biotecnologia e } \\
\text { microbiologia aplicada }\end{array}$ & 1,5 & 3,4 & 7,8 & 6,1 & 4,1 & 4,2 & 5,2 & 4,8 & 5,4 \\
\hline 6 & $\begin{array}{l}\text { Endocrinologia, } \\
\text { metabolismo e nutrição }\end{array}$ & 4,0 & 6,4 & 7,7 & 8,2 & 7,3 & 7,5 & 7,2 & 6,3 & 7,4 \\
\hline 7 & Farmacologia & 2,3 & 4,1 & 6,4 & 5,6 & 6,1 & 6,3 & 4,5 & 4,3 & 5,5 \\
\hline 8 & Fisiologia & 1,8 & 4,8 & 6,2 & 5,9 & 6,3 & 4,3 & 3,9 & 6,0 & 5,4 \\
\hline 9 & Imunologia & 4,3 & 9,7 & 15,8 & 12,3 & 9,9 & 8,5 & 9,4 & 10,1 & 11,0 \\
\hline 10 & Microbiologa & 3,2 & 6,3 & 9,0 & 9,0 & 7,5 & 6,6 & 7,6 & 6,9 & 7,8 \\
\hline & Neurociências & 4,1 & 7,3 & 8,6 & 9,3 & 8,6 & 7,7 & 6,4 & 7,5 & 8,0 \\
\hline Mé & dias dos Países & 3,3 & 8,0 & 10,8 & 10,2 & 9,2 & 8,5 & 8,0 & 8,2 & 9,2 \\
\hline
\end{tabular}

Fonte: Science Indicators 2001. Base de acesso Deluxe. Institute for Scientific Information (ISI), EUA. 


\section{Capacitação científica}

Apesar das deficiências ainda apresentadas no componente qualitativo, o extraordinário desempenho da ciência brasileira guarda paralelismo inequívoco com o processo de formação de recursos humanos em C\&T, centrado no reconhecido sucesso da pós-graduação, iniciada também no final da década de 1960 , contando com 1.812 cursos de mestrado, dos quais 979 de doutorado ao final do ano 2001. Ainda relevante é a presença igualmente efetiva de um forte Programa de Iniciação Científica, que atrai e treina hoje mais de 30.000 jovens universitários que se iniciam, a cada ano, nas atividades de pesquisa científica e tecnológica. É impossível desvincular o componente quantitativo no desempenho científico acima mencionado. Como no futebol e nas artes, o componente quantitativo subsidia o sucesso qualitativo. Sabidamente, a presença da ciência brasileira na bibliografia internacional somente tornou-se significativa a partir do final da década de 1960, após a criação da pós-graduação e desde então tem crescido continuamente. Os processos de capacitação de recursos humanos em C\&T alimentam a formação e a consolidação dos grupos de pesquisa formando, no conjunto, um eficiente ciclo virtuoso, executado predominantemente nas universidades públicas a partir de meados dos anos 60 . Na verdade, o avanço quali-quantitativo mostrado acima para as publicações pode ser estabelecido para o processo de formação de recursos humanos na pós-graduação e consolidação dos grupos de pesquisa: saímos de um limite próximo de zero, no começo dos anos 60 , para a produção de 19.630 dissertações de mestrado e 6.042 teses de doutorado no ano de 2001, e a consolidação de 15.158 grupos de pesquisa a partir de cerca de 400 grupos, no começo da década de 1970 . Portanto, ao longo dos últimos 40 anos, saímos de uma condição quase incipiente em C\&T para o quadro de desempenho que hoje conhecemos. Igualmente significativo foi o impacto em diversas áreas tecnológicas.

A tabela 12 resume os dados relativos à capacitação científica do Brasil nas áreas médica e biomédica, destacando a capacidade instalada de pesquisa representada pelo número de grupos de pesquisa estabelecidos no País bem como a capacidade de formação de novos pesquisadores tomando como base dados dos programas de pós-graduação das respectivas áreas. Diferentemente das tabelas 5, 6 e 7, aqui sepa- ramos, para efeito de melhor comparação, os dados das áreas da medicina, saúde coletiva e odontologia e juntamos numa só entrada os dados das 11 subáreas biomédicas (Tabelas 9, 10 e 11). Verifica-se que juntas as quatro áreas com 3.133 grupos de pesquisa representam $20,7 \%$ do total de 15.158 grupos de pesquisa do Brasil identificados no censo 2002 pelo Diretório dos Grupos de Pesquisa-CNPq. No ranking dos grupos de pesquisa (76 áreas), a medicina com 925 grupos ocupa a primeira posição; a saúde coletiva, a 9ạ; e a odontologia, a 10a. Na área biomédica, os grupos de pesquisa estão distribuídos na bioquímica (274), genética (249), microbiologia (220), fisiologia (136), parasitologia (133), morfologia (130), farmacologia (124), imunologia (119) e biofísica (60), que englobam, praticamente, todos os grupos de pesquisa das 11 subáreas da área biomédica listadas nas tabelas de desempenho (Tabelas 9 a 11).

A discriminação dos componentes dos grupos de pesquisa em pesquisadores, pesquisadores-doutores, líderes de grupos, número de estudantes e linhas de pesquisa, aponta também uma participação relativa conjunta das quatro áreas em torno de $20 \%$ em todos os componentes. A área biomédica contribui com cerca de metade dessa participação, seguida da medicina $(28 \%)$ e da saúde coletiva e odontologia em partes iguais. Na comparação com os dados de desempenho científico mostrado nas tabelas 3 e 4 constata-se que a participação dessas quatro áreas na produção quali-quantitativa da pesquisa brasileira é muito maior (36\%) do que os $20 \%$ representados pelo somatório de sua inserção no conjunto dos grupos de pesquisa no Brasil.

Quanto à capacidade instalada para formação de novos pesquisadores via programas de pós-graduação, também mostrada na tabela 12 , verifica-se que as quatro áreas com um total de 380 programas de pós-graduação contribuem com $21 \%$ de todos os cursos (1.812) reconhecidos pela Capes no final de 2001. A participação dessas áreas é muito mais destacada no doutorado com uma contribuição mais que dobrada (270 ou $27,6 \%$ do total de 979 programas) em relação ao mestrado (95 ou 13,2\% dos 721 cursos). Como já mencionado, isto se deve ao maior grau de maturidade de várias subáreas em relação ao conjunto da ainda jovem pósgraduação brasileira. Um aspecto que chama atenção na tabela 12 é o surgimento recente dos cursos de mestrado profissional, especialmente 


\begin{tabular}{|c|c|c|c|c|c|c|c|c|c|c|c|}
\hline \multicolumn{12}{|c|}{$\begin{array}{l}\text { Tabela } 12 \\
\text { Capacitação científica do Brasil em medicina, odontologia, saúde coletiva e ciências biomédicas. } \\
\text { Dados sobre a capacidade instalada e sobre a formação de recursos humanos. }\end{array}$} \\
\hline \multirow{3}{*}{$\begin{array}{l}\text { Capacidade Instalada } \\
\text { Grupos de Pesquisa e } \\
\text { Programas de Pós-Graduação }\end{array}$} & \multirow{3}{*}{$\begin{array}{l}\text { Brasil } \\
\text { Todas as } \\
\text { Áreas }\end{array}$} & \multicolumn{8}{|c|}{ Áreas Selecionadas } & \multirow{2}{*}{\multicolumn{2}{|c|}{$\begin{array}{c}\text { Total Áreas } \\
\text { Selecionadas }\end{array}$}} \\
\hline & & \multicolumn{2}{|c|}{ Medicina } & \multicolumn{2}{|c|}{ Saúde Coletiva } & \multicolumn{2}{|c|}{ Odontologia } & \multicolumn{2}{|c|}{ Biomédica } & & \\
\hline & & Número & $\%$ & Número & $\%$ & Número & $\%$ & Número & $\%$ & Número & $\%$ \\
\hline Grupos de Pesquisa & 15.158 & 925 & 6,1 & 388 & 2,6 & 375 & 2,5 & 1.445 & 9,5 & 3.133 & 20,7 \\
\hline Pesquisadores ${ }^{\star}$ & 68.291 & 3.535 & 5,2 & 2.115 & 3,1 & 1.500 & 2,2 & 5.997 & 8,8 & 13.147 & 19,3 \\
\hline Pesquisadores-doutores ${ }^{*}$ & 43.356 & 2.482 & 5,7 & 1.018 & 2,3 & 966 & 2,2 & 4.758 & 11,0 & 9.224 & 21,3 \\
\hline Líderes de grupos* & 21.859 & 1.244 & 5,7 & 559 & 2,6 & 500 & 2,3 & 2.073 & 9,5 & 4.376 & 20,0 \\
\hline Estudantes ${ }^{\star}$ & 67.524 & 2.889 & 4,3 & 1.347 & 2,0 & 1.274 & 1,9 & 8.405 & 12,4 & 13.915 & 20,6 \\
\hline Linhas de Pesquisa* & 50.473 & 3.307 & 6,6 & 1.178 & 2,3 & 1.234 & 2,4 & 5.093 & 10,1 & 10.812 & 21,4 \\
\hline Médias & - & - & 5,6 & - & 2,5 & - & 2,3 & - & 10,2 & - & 20,6 \\
\hline Programas de Pós-Graduação & 1.812 & 178 & 9,8 & 27 & 1,5 & 85 & 4,7 & 90 & 5,0 & 380 & 21,0 \\
\hline Mestrado & 721 & 36 & 5,0 & 16 & 2,2 & 27 & 3,7 & 16 & 2,2 & 95 & 13,2 \\
\hline Doutorado & 979 & 139 & 14,2 & 11 & 1,1 & 46 & 4,7 & 74 & 7,6 & 270 & 27,6 \\
\hline Mestrado profissional & 112 & $7^{* *}$ & 6,3 & $3^{* * *}$ & 2,7 & 12 & 10,7 & $4^{* * *}$ & 3,6 & 26 & 23,2 \\
\hline Total de docentes ${ }^{\star}$ & 30.894 & 2.338 & 7,6 & 580 & 1,9 & 826 & 2,7 & 1.874 & 6,1 & 5.618 & 18,2 \\
\hline Docentes com doutorado* & 30.160 & 2.317 & 7,7 & 571 & 1,9 & 812 & 2,7 & 1.859 & 6,2 & 5.559 & 18,4 \\
\hline Alunos matriculados ${ }^{\star * * *}$ & 100.008 & 6.461 & 6,5 & 1.991 & 2,0 & 2.089 & 2,1 & 5.209 & 5,2 & 15.750 & 15,7 \\
\hline - mestrado & 61.928 & 3.678 & 5,9 & 1.180 & 1,9 & 1.175 & 1,9 & 2.530 & 4,1 & 8.563 & 13,8 \\
\hline - doutorado & 35.102 & 2.737 & 7,8 & 750 & 2,1 & 736 & 2,1 & 2.617 & 7,5 & 6.840 & 19,5 \\
\hline - mestrado profissional & 2.978 & 46 & 1,5 & 61 & 2,0 & 178 & 6,0 & 62 & 2,1 & 347 & 11,7 \\
\hline Titulados ${ }^{* * * *}$ & 26.028 & 1.670 & 6,4 & 510 & 2,0 & 846 & 3,3 & 1.417 & 5,4 & 4.443 & 17,1 \\
\hline - mestrado & 19.630 & 1.057 & 5,4 & 390 & 2,0 & 541 & 2,8 & 913 & 4,7 & 2.901 & 14,8 \\
\hline - doutorado & 6.042 & 613 & 10,1 & 120 & 2,0 & 205 & 3,4 & 504 & 8,3 & 1.442 & 23,9 \\
\hline - mestrado profissional & 356 & 0 & 0,0 & 0 & 0,0 & 100 & 28,1 & 0 & 0,0 & 100 & 28,1 \\
\hline
\end{tabular}

* Dados sem dupla contagem.

** Quatro dos sete mestrados profissionais já estão incluídos nos cursos de mestrado e doutorado acadêmicos.

*** Já incluídos nos cursos de mestrado e doutorado acadêmicos. Nesses casos o total se refere à soma mestrado + doutorado.

**** Dados referentes ao final do ano 2001

Fontes: Diretório dos Grupos de Pesquisa-CNPq-MCT. Censo 2002. Dados Capes 2002: www.capes.gov.br

na odontologia e um pouco menor na medicina, que já respondem por $10,7 \%$ e $6,3 \%$ respectivamente do total da Capes (112 cursos no final de 2001). Como seria de esperar, o surgimento de tais cursos é incipiente na saúde coletiva e na área biomédica.

No que concerne à capacidade de orientação na pós-graduação, a medicina e a odontologia com cerca de 13 e 10 pesquisadores-doutores em média por programa de pós-graduação apresentam tais índices em proporção bem inferior à média de todas as áreas da pós-graduação no Brasil (17 pesquisadores-doutores por programa de pós-graduação) e muito mais ainda em relação às áreas de saúde coletiva e biomédica, que têm 21 pesquisadores-doutores por programa. Isto ocorre porque há na medicina e na odontologia uma proporção maior de cursos credenciados como acadêmicos que têm, na verdade, características profissionalizantes, sendo de se esperar crescimento de mestrados profissionais nessas duas áreas. Destaque-se que tal situação é também apresentada por várias áreas da Capes e que os mestrados profissionais são um instrumento excelente de formação pós-graduada para capacitação de recursos humanos para o mercado de trabalho não-acadêmico, o qual vem demandando, crescentemente, pessoal qualificado que a formação graduada nas IES não tem tido capacidade de oferecer.

Uma relação inesperada é a apresentada pela comparação do número de pesquisadoresdoutores do DGP com o número de docentes com doutorado dos programas de pós-graduação. Enquanto na medicina e na odontologia esta relação tem variação muito pequena $(2.482$ versus 2.317 na medicina e 966 versus 826 na odontologia), na saúde coletiva e no conjunto da área biomédica a variação chega a $78 \%$ e $66 \%$ nas duas áreas (1.018 versus 571 e 9.224 
versus 5.559), respectivamente. Enquanto na saúde coletiva tal discrepância pode indicar existência de um número considerável de pesquisadores-doutores atuando em projetos de pesquisa desvinculados da área acadêmica, na área biomédica, reflete seguramente, um elevado contingente de jovens doutores sem vínculo empregatício com as instituições de ensino e pesquisa que constitui seu mercado genuíno de trabalho formal. De qualquer maneira, nas duas áreas, tal situação revela a existência de um grande contingente de pessoal qualificado desvinculado dos programas de formação de novos pesquisadores via pós-graduação. Sabidamente isto vem ocorrendo em face da drástica redução dos concursos para reposição dos quadros docentes, especialmente nas IES públicas. Constitui, portanto, situação de risco para o Brasil a manutenção deste quadro que desen- cadeia a possibilidade de perda de jovens talentos, bem treinados para a pesquisa, pela oportunidade continuamente oferecida de melhores condições de trabalho em instituições estrangeiras.

Quanto ao número de alunos matriculados e titulados na pós-graduação, a tabela 12 mostra que as quatro áreas contribuem com 15,7\% (15.750 alunos) num total de 100 mil alunos matriculados ao final de 2001. No doutorado a participação é ainda maior (6.840 ou 19,5\% dos 35.102 matriculados no Brasil em todas as áreas). No ano de 2001 foram titulados 4.443 pós-graduados, sendo 2.901 (14,8\% no total brasileiro) no mestrado acadêmico e 100 no mestrado profissional $(28,1 \%)$, estes últimos, todos na odontologia. A contribuição das quatro áreas foi mais destacada no doutorado com 1.442 doutores formados em 2001, correspon-

\section{Tabela 13}

Áreas e subáreas de pesquisa com cinco ou mais programas de pós-graduação na área médica e biomédica.

\begin{tabular}{|c|c|c|c|c|c|c|}
\hline \multirow[t]{2}{*}{ No } & \multirow[t]{2}{*}{ Áreas e Subáreas } & \multicolumn{5}{|c|}{ Programas de Pós-Graduação } \\
\hline & & Mestrado & Doutorado & $\begin{array}{l}\text { Mestrado e } \\
\text { Doutorado }\end{array}$ & $\begin{array}{l}\text { Mestrado } \\
\text { Profissional }\end{array}$ & Total \\
\hline 1 & Bioquímica e biofísica & 3 & - & 16 & - & 19 \\
\hline 2 & Cardiologia & 1 & 1 & 4 & 1 & 6 \\
\hline 3 & Ciências da saúde & 6 & - & 3 & - & 9 \\
\hline 4 & Cirurgia & 1 & 2 & 17 & - & 20 \\
\hline 5 & Farmacologia & 3 & - & 7 & 1 & 11 \\
\hline 6 & Fisiologia & 3 & - & 10 & 1 & 14 \\
\hline 7 & Gastroenterologia e hepatologia & 1 & - & 5 & - & 6 \\
\hline 8 & Genética & 3 & - & 15 & - & 18 \\
\hline 9 & Ginecologia, obstetrícia e tocoginecologia & 2 & - & 8 & - & 10 \\
\hline 10 & Imunologia & - & - & 5 & - & 5 \\
\hline 11 & Imunologia clínica e doenças infecciosas & 1 & - & 4 & - & 5 \\
\hline 12 & Medicina interna geral $(\mathrm{d})$ & 1 & - & 3 & 1 & 5 \\
\hline 13 & Medicina, tópicos gerais (f) & 5 & 1 & 16 & - & 22 \\
\hline 14 & Medicina tropical & 2 & - & 7 & - & 9 \\
\hline 15 & Microbiologia & 2 & - & 7 & - & 9 \\
\hline 16 & Morfologia & 1 & - & 7 & 1 & 9 \\
\hline 17 & Neurologia (g) & - & - & 4 & 1 & 5 \\
\hline 18 & Odontologia & 27 & 2 & 44 & 12 & 85 \\
\hline 19 & Ortopedia e traumatologia & 2 & - & 3 & 1 & 6 \\
\hline 20 & Parasitologia & 1 & - & 4 & - & 5 \\
\hline 21 & Patologia e anatomia patológica & 4 & 1 & 9 & - & 14 \\
\hline 22 & Pediatria $(\mathrm{h})$ & 5 & - & 9 & - & 14 \\
\hline 23 & Psiquiatria, psicologia clínica e psicanálise & 2 & - & 6 & - & 8 \\
\hline 24 & Saúde coletiva & 16 & - & 11 & - & 27 \\
\hline 25 & Outras 13 sub-áreas da medicina ${ }^{*}$ & 3 & 3 & 26 & 7 & 39 \\
\hline Tot & & 95 & 10 & 260 & $26^{* *}$ & 380 \\
\hline
\end{tabular}

* As 13 subáreas da medicina com menos de cinco cursos inclui: anestesiologia (2), pneumologia (3), dermatologia (3), endocrinologia (4), reumatologia (2) e urulogia (3).

** Dos 26 mestrados profissionais 11 estão incluídos em programas de mestrado e doutorado.

Fonte: Diretório dos Grupos de Pesquisa-CNPq, Censo 2002. Dados CAPES 2002: www.capes.gov.br 
dendo a $24 \%$ do total brasileiro de 6.042 doutores naquele ano.

A tabela 13 apresenta a distribuição dos programas de pós-graduação nas subáreas da medicina, na saúde coletiva, na odontologia e nas subáreas da área biomédica. Estão listadas as áreas e subáreas com pelo menos cinco programas de pós-graduação (cursos de mestrado, doutorado, mestrado e doutorado e os mestrados profissionais) reconhecidos pela Capes, com base nos dados do final de 2001. Verificase que a grande maioria das áreas/subáreas oferece programas de pós-graduação possibilitando abranger a formação de recursos humanos para os diversos campos de pesquisa de cada uma das áreas no Brasil.

\section{Conclusão}

Os dados apresentados demonstram claramente que a pesquisa médica e biomédica no Brasil vem alcançando sucessivo progresso especialmente no componente quantitativo, com um crescimento extraordinário nas publicações científicas. Também no que diz respeito ao progresso qualitativo há vários destaques pontuais e ainda na melhoria do desempenho coletivo. Verifica-se, ademais, que essas áreas estão plenamente capacitadas para dar continuidade ao processo de formação de novos pesquisadores, em compasso compatível com o desempenho científico demonstrado nesses últimos 20 anos, como fartamente ilustrado nas tabelas apresentadas. Ressalte-se, todavia, que tanto o desempenho obtido, como a capacidade instalada de pesquisa e bem assim a de capacitação de novos pesquisadores, se situam ainda muito aquém dos índices necessários para o enfrentamento dos gigantescos desafios sociais e econômicos que o País apresenta nesta e em outras áreas. O ritmo de crescimento na capacitação e qualificação de novos pesquisadores pode ser suficiente para manter nosso desempenho atual, mas é insuficiente para a competição, já estabelecida, não apenas com os países mais desenvolvidos, mas especialmente com aqueles outros países em situação semelhante à nossa e que são nossos concorrentes diretos (Coréia do Sul, China, Taiwan, Espanha) e que vêm apresentando desempenho superior ao que vimos obtendo, apesar dos destacados avanços, no campo da pesquisa científica e tecnológica.

\section{Referências bibliográficas}

Capes 2002. Disponível em <www.capes.gov.br>. Acesso em março de 2003.

Diretório dos Grupos de Pesquisa (Censo 2002). Disponível em <http://www.cnpq.gov.br>. CNPq-MCT, Brasília. Acesso abril de 2003.

Gomes J \& Guimarães JA 2001. Capacitação, desempenho e conhecimento acumulado indicam oportunidades em áreas de inovação tecnológica no Brasil. Simpósio de Inovação Tecnológica, FEA-USP. (No prelo).

Guimarães JA \& Gomes J 2001. Duas décadas de desempenho científico excepcional na América Latina, pp. 69-90. In AP Trossero. Los laberintos del futuro. Universidad del Litoral, Santa Fé, Argentina.

Indicators 2001, disponibilizado em CD-Rom. Institute for Scientific Information (ISI), Filadélfia, EUA.

Narim F, Hamilton KS \& Olivastro D 1997. The increasing linkage between U.S. technology and public science. Research Policy 26:317-330
PISA 2000 - Programa Internacional de Avaliação de Alunos, Organização para Cooperação e Desenvolvimento Econômico (OCDE), 2000.

Web of Science 2002. Institute for Scientific Information (ISI) Philadelphia, EUA. Disponível no Portal de Periódicos, CAPES.

World Development Indicators (WDI) - World Bank Groups, World Bank, 2001. Disponível em <http:// www.worldbank.org/> e <http://www.worldbank. org/data/wdi2001>. Acesso em março de 2003.

Artigo apresentado em 8/12/2003

Aprovado em 17/2/2004

Versão final apresentada em 2/3/2004 